\title{
General Subdomain Model for Predicting Magnetic Field in Internal and External Rotor Multiphase Flux-Switching Machines Topologies
}

\author{
K. Boughrara ${ }^{1}$, T. Lubin ${ }^{2}$, R. Ibtiouen ${ }^{3}$ \\ ${ }^{1}$ Université de Khemis-Miliana, Laboratoire de l'Energie et des Systèmes Intelligents (LESI), Route de Theniet El-had, Khemis- \\ Miliana, 44225, Algeria \\ ${ }^{2}$ Université de Lorraine, Groupe de Recherche en Electrotechnique et Electronique de Nancy, GREEN, EA 4366, F-54506 \\ Vandoeuvre-lès-Nancy, France \\ ${ }^{3}$ Ecole Nationale Polytechnique (LRE-ENP), Algiers, 10, av. Pasteur, El Harrach, BP182, 16200, Algeria
}

\begin{abstract}
This paper presents a general analytical subdomain model for the computation of magnetic field distribution in any number of stator slots and rotor poles with and without electrically-excited, permanent magnet-excited and hybrid-excited multiphase flux switching machines (FSM) topologies. The goal of this work is to elaborate an analytical general method based on subdomain model for predicting magnetic field in any FSM topology with defining in advance the number of subdomains and affect the general form of vector potential in each subdomain. The presented general subdomain method is comparable to finite element method (FEM) where the mesh elements can be compared to the number of harmonic terms used in each subdomain.
\end{abstract}

Index Terms - General subdomain model, magnetic field, flux switching machines, finite element method.

\section{INTRODUCTION}

$I^{n}$ ndustrial demands are increasing for electromagnetic topologies combining high torque density, high efficiency and robustness. Hence, the Permanent Magnet-Flux Switching machine (PM-FSM) appears to be an excellent candidate. Indeed, this machine combines advantages of brushless PM machines having a high torque density, and those of switched reluctance machines (SRM) [1]-[4]. Nevertheless, the high flux control capability, required for variable speed applications, led designers to propose HybridExcited Flux-Switching machines (HE-FSM) [5]-[9]. An additional wound exciter is combined with the PM to allow a good flux regulation. Currently, the current increase in rareearth PM prices, combined with risks of shortages, pose great issues of cost and supply delays. To overcome these problems the electrically-Excited Flux-Switching machine (EE-FSM) was proposed [8].

Regarding the modeling of FSM, mainly Finite Element (FEM) methods are considered because of the inherent doubly-salient air-gap and the non-linear behavior of magnetic material. Despite their proven accuracy, FE simulations suffer from severe computational time requirements and offer limited ability to explore numerous designs. To overcome this problem, some authors proposed models of PM-FSM, HEFSM and FE-FSM topologies in a more analytical manner, using Magnetic Equivalent Circuit (MEC) [10]-[11] or Fourier analysis methods based on subdomain model [12] or slot relative permeance calculation [13]-[14]. The subdomain model is more accurate than MEC and relative permeance calculation based model [10]. Of course, only radial flux density in the doubly salient air gap is calculated with the proposed method and the magnetic interaction between the slots is not taken into account [13]-[14], which is a problem for the tangential force computation by the Maxwell stress tensor method and cannot handle with PM-FSM and HE-FSM topologies. To authors' knowledge, only Gysen et al. in [12] have proposed an exact analytical subdomain model for the prediction of magnetic field (radial and tangential components) in a 12/10 PM-FSM. However, it can be seen in our paper that, it is not necessary to set the divergence of the magnetic flux density around the stator to zero to solve the unknown coefficients in permanent magnet region. Subdomain model is well known in magnetic field analytical prediction for permanent magnet machines [15]-[23]. It consists of solving directly the field governing equations (Laplacian and/or quasi-Poissonian equations) in different domains to obtain the overall field distribution by applying boundary conditions on the interfaces between each subdomain. No references in the literature addressing the issue of an analytical model for SRM, EE-FSM and HE-FSM machines were found.

In this paper, a general formulation of subdomain model for prediction magnetic field distribution in any number of stator slots and rotor poles combinations of multiphase internal and external rotor SRM, EE-FSM, PM-FSM and HE-FSM topologies is presented. Only some internal rotor topologies are developed for the sake of clarity. However, other internal and external rotor configurations magnetic field results are given in the appendix A. The objective of the paper is to elaborate a program based on general subdomain model to predict magnetic field in any FSM topology with defining as entry the number of subdomains and the general form of magnetic field in each subdomain. All results from the developed analytical model are then compared to those found by the finite element method (FEM) [24].

\section{Magnetic Field in DifFERENT Subdomains}

There are many topologies of SRM and FSM, constituted by different type of subdomains. Armature stator slots with single or double layer winding, rotor slots, excitation coils stator slots with single or double layer winding, permanent magnet slots. In some topologies, there are slots which have both permanent magnet and excitation coils or armature coils and excitation coils [8]. The proposed model is formulated in vector potential and two-dimensional polar coordinates with the following assumptions 
The stator and rotor cores are assumed to be infinitely permeable.

Eddy current effects are neglected.

The axial length of the machine is infinite i.e. end effects are neglected.

The current density has only one component along the zaxis.

To solve this type of problem by an analytical way, the sides of every region must be in radial or angular direction (directions of the polar coordinates system). Then, we have simplified the geometry of the studied machines by considering that the stator and rotor slots have radial sides [12].

In this section, we give the general solution of the magnetic vector potential in the different regions of a general machine (slots with or without current or with magnets, air-gap ...). Then, we use these solutions to study some particular machines.

\section{A. Armature and Excitation Slot Subdomain}

Magnetic field calculation in the rotor or the stator slots subdomains with single or double layer winding and with one side or two sides open is calculated analytically with solving Poisson's or Laplace equations with the method of separation of variables. To simplify the notations, the magnetic vector potential in a slot is named $A_{i}$ where $i$ is the slot number (stator or rotor slots).

A-1 Single layer winding

In each slot subdomain (i) (Fig. 1), we have to solve Poisson's equation

$$
\frac{\partial^{2} A_{i}}{\partial r^{2}}+\frac{1}{r} \frac{\partial A_{i}}{\partial r}+\frac{1}{r^{2}} \frac{\partial^{2} A_{i}}{\partial \theta^{2}}=-\mu_{0} J_{i}
$$

where $J_{i}$ is a constant current density in the whole surface of the slot $i$.

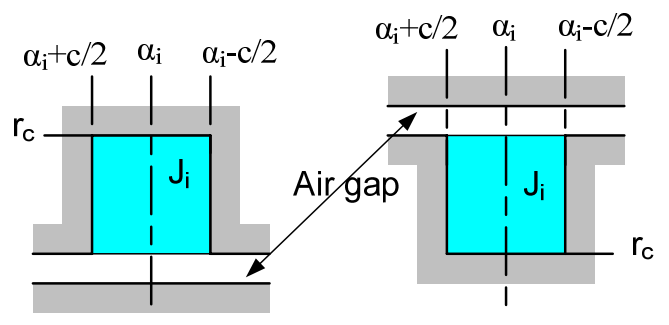

a)

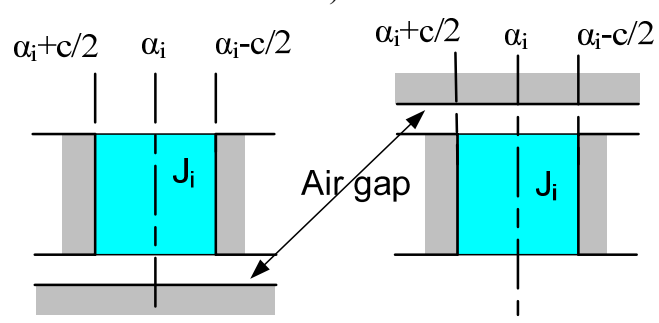

b)

Fig. 1. Stator or rotor slot subdomain (i) with single layer winding. a) Open slot on one side. b) Open slot on two sides.
The tangential component of the magnetic field at the sides and at the bottom of the slot is null (infinite permeability for iron core). Therefore, the ith slot subdomain (Fig. 1.a.) is associated with the following boundary conditions

$$
\begin{aligned}
& \left.\frac{\partial A_{i}}{\partial \theta}\right|_{\theta=\alpha_{i}-\frac{c}{2}}=0 \text { and }\left.\frac{\partial A_{i}}{\partial \theta}\right|_{\theta=\alpha_{i}+\frac{c}{2}}=0 \\
& \left.\frac{\partial A_{i}}{\partial r}\right|_{r=r_{c}}=0
\end{aligned}
$$

where $\alpha_{i}$ is the angular position of the $i t h$ slot and $c$ the slot opening in radian.

The boundary conditions (2) and (3), leads to the general solution of equation (1) with only two integration constants $\mathrm{C}_{\mathrm{i}, 0}$ and $\mathrm{C}_{\mathrm{i}, \mathrm{m}}$ as shown in (4).

$$
\begin{aligned}
& A_{i}(r, \theta)=C_{i, 0}+\frac{1}{2} \mu_{0} J_{i} r_{c}^{2} \ln (r)-\frac{1}{4} \mu_{0} J_{i} r^{2} \\
& +\sum_{m=1}^{\infty} C_{i, m} f_{m}(r) \cos \left(\frac{m \pi}{c}\left(\theta-\alpha_{i}+\frac{c}{2}\right)\right) \\
& \text { with } f_{m}(r)=r^{-\frac{m \pi}{c}}+\frac{r_{c}^{-\frac{m \pi}{c}} r^{\frac{m \pi}{c}}}{r_{c}^{\frac{m \pi}{c}}}
\end{aligned}
$$

where $m$ is a positive integer.

In the case where the slot is open on the two sides (Fig. 1.b.), the boundary condition ( 3 ) is omitted and the general solution of (1) is

$$
\begin{gathered}
A_{i}(r, \theta)=C 1_{i, 0}+C 2_{i, 0} \ln (r)-\frac{1}{4} \mu_{0} J_{i} r^{2} \\
+\sum_{m=1}^{\infty}\left[C 1_{i, m} r^{-\frac{m \pi}{c}}+C 2_{i, m} r^{\frac{m \pi}{c}}\right] \cos \left(\frac{m \pi}{c}\left(\theta-\alpha_{i}+\frac{c}{2}\right)\right)
\end{gathered}
$$

In this case, we have four integration constants $\left(C_{1,0}, C_{2,0}\right.$, $C 1_{i, m}$ and $\left.C 2_{i, m}\right)$ to determine.

A-2 Double layer winding

The slot contains two coils as shown in Fig. 2. The Fourier series expansion of the current density is

$J_{i}(\theta)=J_{i, 0}+\sum_{m=1}^{\infty} J_{i, m} \cos \left(\frac{m \pi}{c}\left(\theta-\alpha_{i}+\frac{c}{2}\right)\right)$

where $J_{i, 0}=\frac{J_{i, 1} d+J_{i, 2} d}{c}$ and

$J_{i, m}=\frac{2}{m \pi} \sin \left(\frac{m \pi d}{c}\right)\left(J_{i, 1}+(-1)^{m} J_{i, 2}\right)$

where $J_{i, 1}$ and $J_{i, 2}$ are the current densities of the corresponding slot region i with the thickness $d$. 


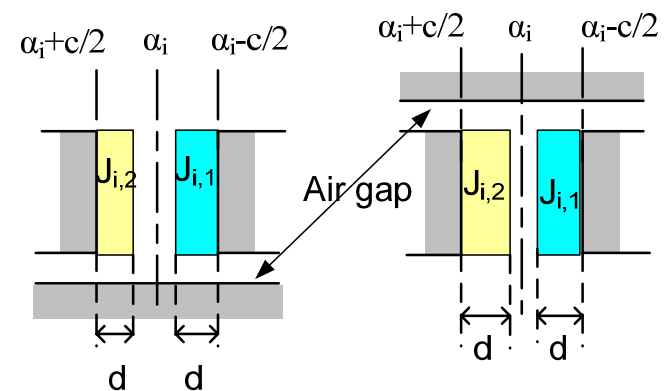

a)

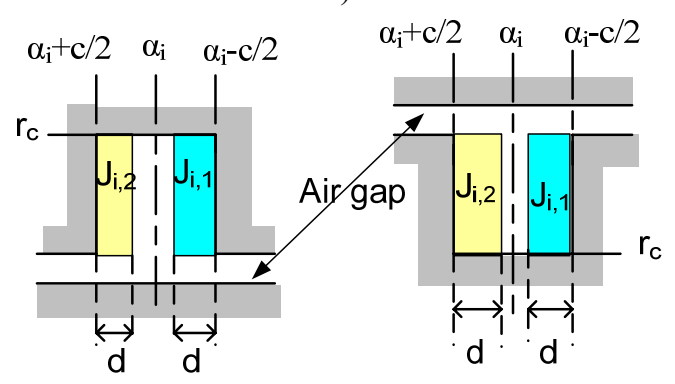

b)

Fig. 2. Stator or rotor slot subdomain (i) with double layer winding. a) Open slot on two sides. b) Open slot on one side.

Replacing (6) in (1) and taking into account the boundary equations (2) (Fig. 2.a.), leads to the general solution of equation (1)

$$
\begin{gathered}
A_{i}(r, \theta)=C 1_{i, 0}+C 2_{i, 0} \ln (r)-\frac{1}{4} \mu_{0} J_{i, 0} r^{2} \\
+\sum_{m=1}^{\infty}\left(C 1_{i, m} r^{-\frac{m \pi}{c}}+C 2_{i, m} r^{\frac{m \pi}{c}}+F_{i, m} r^{2}\right) \cos \left(\frac{m \pi}{c}\left(\theta-\alpha_{i}+\frac{c}{2}\right)\right)
\end{gathered}
$$$$
\text { where } F_{i, m}=\frac{\mu_{0} J_{i, m} c^{2}}{m^{2} \pi^{2}-4 c^{2}}
$$

The case $m \pi=2 c$ can be solved easily.

For the case where slot is open on one side only (Fig. 2.b), the boundary condition (3) is introduced to get

$$
\begin{aligned}
& A_{i}(r, \theta)=C_{i, 0}+\frac{1}{2} \mu_{0} J_{i, 0} r_{c}^{2} \ln (r)-\frac{1}{4} \mu_{0} J_{i, 0} r^{2} \\
& +\sum_{m=1}^{\infty}\left(C_{i, m} f_{m}(r)-G_{i, m} r^{\frac{m \pi}{c}}+F_{i, m} r^{2}\right) \cos \left(\frac{m \pi}{c}\left(\theta-\alpha_{i}+\frac{c}{2}\right)\right) \\
& \text { where } G_{i, m}=\frac{2 F_{i, m} r_{c}^{2} c}{r_{c}^{\frac{m \pi}{c}} m \pi}
\end{aligned}
$$

It is important to note here that the solutions (4) and (5) corresponding to the single layer excistation can be deduced respectively from (8) and (7) by imposing $J_{i, 1}=J_{i}, J_{i, 2}=0$ and $d=c$.

\section{B. Permanent Magnet Subdomain}

In each permanent magnet subdomain (i) (Fig. 3), we have to solve Poisson's equation. We consider that the magnetization of permanent magnet is purely tangential.

$$
\frac{\partial^{2} A_{i}}{\partial r^{2}}+\frac{1}{r} \frac{\partial A_{i}}{\partial r}+\frac{1}{r^{2}} \frac{\partial^{2} A_{i}}{\partial \theta^{2}}=-\mu_{0} \frac{M_{\theta}}{r}
$$

where $M_{\theta}=M_{i}=(-1)^{i} \frac{B_{r e m}}{\mu_{0}}$

For $N s$ permanent magnet, i vary from 1 to $N s$ and $B_{r e m}$ is the remanence of magnetization.

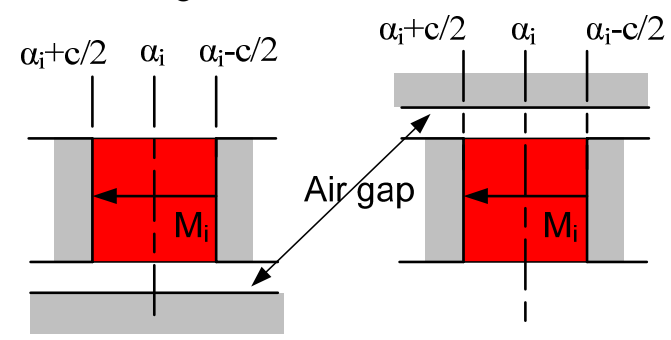

a)

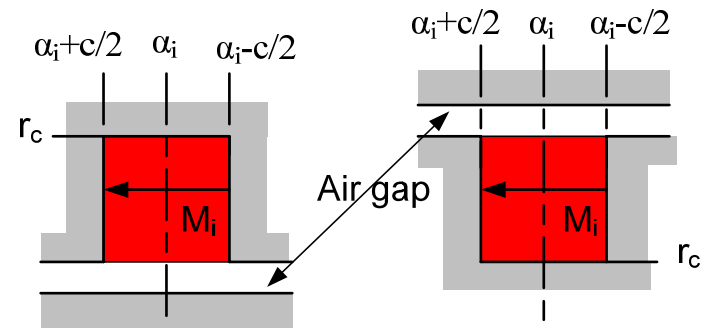

b)

Fig. 3. Stator or rotor permanent magnet subdomain (i). a) Open magnet on two sides. b) Open magnet on one side.

For subdomain with permanent magnet slot open on two sides (Fig. 3.a) and taking into account the boundary condition (2), the general solution of (9) is given by

$$
\begin{aligned}
& A_{i}(r, \theta)=C 1_{i, 0}+C 2_{i, 0} \ln (r)-\mu_{0} M_{i} r \\
& +\sum_{m=1}^{\infty}\left(C 1_{i, m} r^{-\frac{m \pi}{c}}+C 2_{i, m} r^{\frac{m \pi}{c}}\right) \cos \left(\frac{m \pi}{c}\left(\theta-\alpha_{i}+\frac{c}{2}\right)\right)
\end{aligned}
$$

The case of Fig. 3.b, where permanent magnet slot subdomain is open only on one side, the boundary condition (3) should be introduced and the general solution is

$$
\begin{aligned}
& A_{i}(r, \theta)=C_{i, 0}-\mu_{0} M_{i} r \\
& +\sum_{m=1}^{\infty} C_{i, m} f_{m}(r) \cos \left(\frac{m \pi}{c}\left(\theta-\alpha_{i}+\frac{c}{2}\right)\right)
\end{aligned}
$$

\section{Rotor or Stator Slot Subdomain}

In each rotor or stator slot subdomain (i) without current and permanent magnet (Fig. 4), we have to solve Laplace's equation

$$
\frac{\partial^{2} A_{i}}{\partial r^{2}}+\frac{1}{r} \frac{\partial A_{i}}{\partial r}+\frac{1}{r^{2}} \frac{\partial^{2} A_{i}}{\partial \theta^{2}}=0
$$




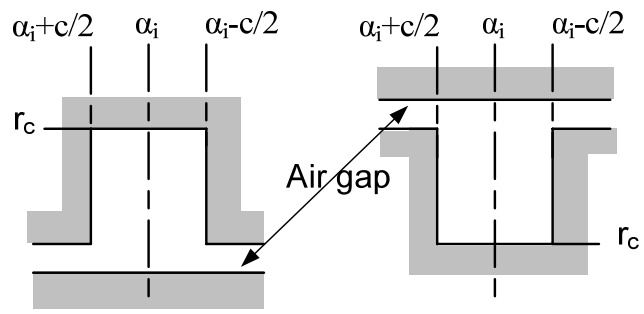

a)

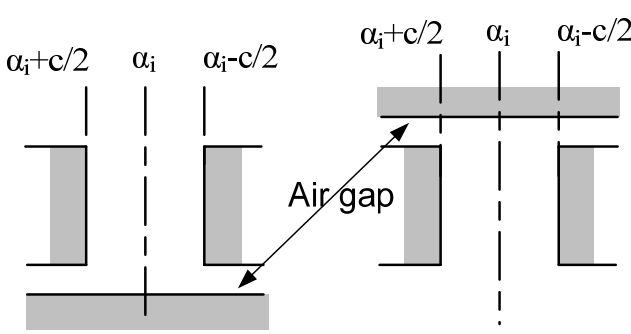

b)

Fig. 4. Stator or rotor slot subdomain (i). a) Open on one side. b) Open on two sides.

The solution can be obtain directly from (11) with $M_{i}=0$

$$
\begin{gathered}
A_{i}(r, \theta)=C_{i, 0} \\
+\sum_{m=1}^{\infty} C_{i, m} f_{m}(r) \cos \left(\frac{m \pi}{c}\left(\theta-\alpha_{i}+\frac{c}{2}\right)\right)
\end{gathered}
$$

For the case of Fig. 4.b with slot open on the two sides, the solution can be obtain directly from (10) with $M_{i}=0$

$$
\begin{aligned}
& A_{i}(r, \theta)=C 1_{i, 0}+C 2_{i, 0} \ln (r) \\
& +\sum_{m=1}^{\infty}\left(C 1_{i, m} r^{-\frac{m \pi}{c}}+C 2_{i, m} r^{\frac{m \pi}{c}}\right) \cos \left(\frac{m \pi}{c}\left(\theta-\alpha_{i}+\frac{c}{2}\right)\right)
\end{aligned}
$$

\section{Combination of Subdomains in a Slot}

Many combinations of subdomains in one slot can be found (Fig. 5). In this case, we have two subdomains, permanent magnet and/or current density subdomains. The current subdomain can be in single or double layer excitation. Opening of subdomain with current density can also be greater or lower than PM subdomain. Permanent magnet subdomain can also be replaced with single or double layer winding. General forms of vector potentials: in permanent magnet subdomain (Figs. 5. a, b) is given by equation (10), in current density subdomain (Fig. 5. a) is given by (4) and in current density subdomain (Fig. 5. b) is given by (5).

Generally, double-layer winding is set as left layer and right layer in the slot for SRM and FSM. However, the double-layer winding can be set as upper layer and lower layer [25] (Figs. 5. c, d). As for the permanent magnet and current density subdomains, the general form of vector potentials: in the coil represented by the current $J_{i l}$ subdomain (Fig. 5. c) is given by equation (4), in the coil $J_{i 2}$ subdomain (Fig. 5. c) is given by (5) and in the coils $J_{i 1}$ and $J_{i 2}$ subdomains (Fig. 5. d) are given by (5). In reference [25], authors have considered this type of double-layer winding as one subdomain. In the general formulation of subdomain model, it is interesting to consider two domains with adding in the analysis an interface condition in the radius $r_{3}$.

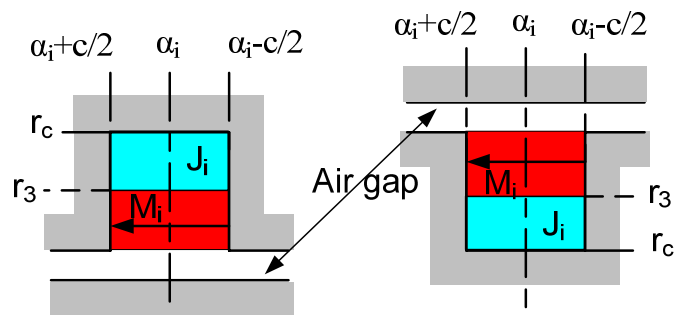

a)

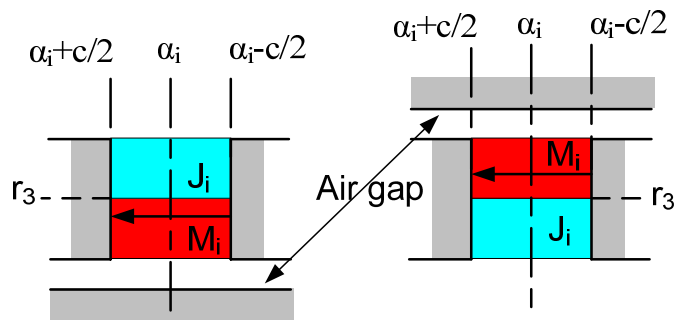

b)

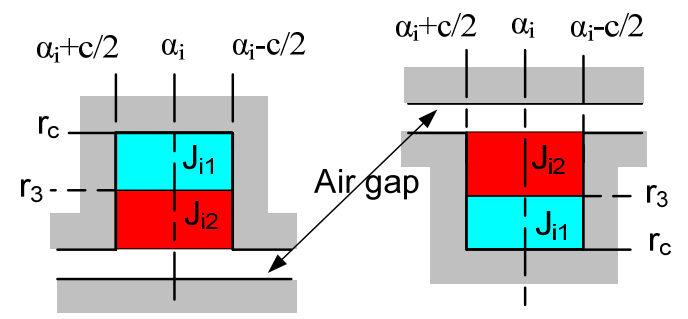

c)

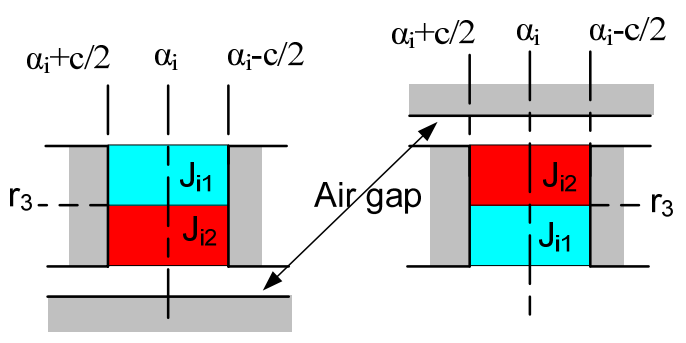

d)

Fig. 5. Slot with two subdomains (i). a) Open on one side. b) Open on two sides. c) Open on one side. d) Open on two sides.

\section{E. Airgap Subdomain}

The magnetic potential in the air-gap region is called $A_{a}$. The Laplace equation (15) in the airgap subdomain which is an annular domain delimited by the radii $R_{m}$ and $R_{s}$ is given by

$\frac{\partial^{2} A a}{\partial r^{2}}+\frac{1}{r} \frac{\partial A a}{\partial r}+\frac{1}{r^{2}} \frac{\partial^{2} A a}{\partial \theta^{2}}=0$

The solution of (15) is well-known and is given by 


$$
\begin{aligned}
A a(r, \theta)= & \sum_{n=1}^{\infty}\left(A 1_{n} r^{n}+A 2_{n} r^{-n}\right) \sin (n \theta) \\
& +\left(A 3_{n} r^{n}+A 4_{n} r^{-n}\right) \cos (n \theta)
\end{aligned}
$$

where $\mathrm{n}$ is a positive integer.

\section{F. Outside Machine and Shaft Subdomains}

For some topologies of FSM, there are permanent magnets or coils that have flux leakage with the outside of the machine for internal rotor and with the shaft for external rotor. In those cases, it is important to add one subdomain to take into account the outside region or the shaft of the machine.

The magnetic potential in these regions are called $A_{o}$. The Laplace's equation (17) in the outside region and in the shaft of the machine (where the relative recoil permeability is equal to 1$)$ is given by

$$
\frac{\partial^{2} A o}{\partial r^{2}}+\frac{1}{r} \frac{\partial A o}{\partial r}+\frac{1}{r^{2}} \frac{\partial^{2} A o}{\partial \theta^{2}}=0
$$

Taking into account the finite value of vector potential at the infinity radius for internal rotor FSM and at null radius for external rotor FSM, the solution of equation (17) is

$$
A o(r, \theta)=\sum_{n=1}^{\infty} A 1_{n} r^{-n} \sin (n \theta)+A 2_{n} r^{-n} \cos (n \theta)
$$

for internal rotor topology, and

$$
A o(r, \theta)=\sum_{n=1}^{\infty} A 1_{n} r^{n} \sin (n \theta)+A 2{ }_{n} r^{n} \cos (n \theta)
$$

for external rotor topology.

To determine Fourier series unknown constants, boundary and interface conditions should be introduced.

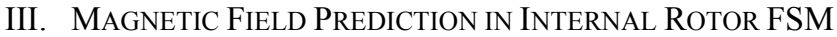 TOPOLOGIES}

The aim of this section is to predict analytically the magnetic field distribution in switching flux machines using a general subdomain model. Many FSM topologies are constituted with a combination of subdomains studied in the above section.

\section{A. $6 / 4$ SRM}

The SRM (Fig. 6) has 6 stator slots, 3 phases' double layer winding and 4 poles. This machine is constituted with three regions: rotor slots region with 4 subdomains, stator slot region with 6 subdomains and air gap region with 1 subdomain.

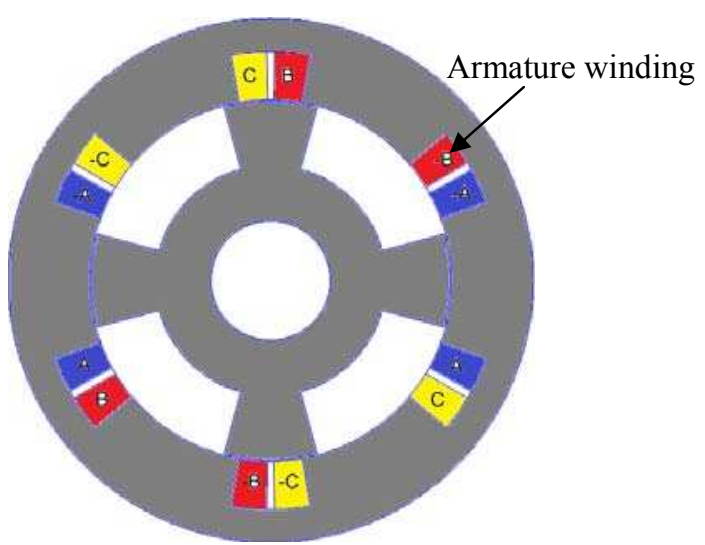

Fig. 6. Studied 6/4 internal rotor SRM.

In internal rotor SRM, the general form of vector potential equations (16), (13) and (8) are used for air gap, rotor slots and stator slots regions respectively as

$$
\begin{aligned}
& A z I(r, \theta)= \sum_{n=1}^{\infty}\left(A 1_{n} r^{n}+A 2_{n} r^{-n}\right) \sin (n \theta) \\
&+\left(A 3_{n} r^{n}+A 4_{n} r^{-n}\right) \cos (n \theta) \\
& A z I I_{j}(r, \theta)= A 5_{j, 0} \\
&+\sum_{m=1}^{\infty} A 5_{j, m} f_{m}(r) \cos \left(\frac{m \pi}{a}\left(\theta-g_{j}+\frac{a}{2}\right)\right) \\
& f_{m}(r)=r^{-\frac{m \pi}{a}}+\frac{r_{1}^{-\frac{m \pi}{a}} r^{\frac{m \pi}{a}}}{r_{1}^{\frac{m \pi}{a}}}
\end{aligned}
$$

where $g_{j}$ is the angular position of the $j$ th rotor slot and $a$ the slot opening in radian.

$$
\begin{aligned}
& A z I I I_{i}(r, \theta)=C_{i, 0}+\frac{1}{2} \mu_{0} J_{i, 0} r_{4}^{2} \ln (r)-\frac{1}{4} \mu_{0} J_{i, 0} r^{2}(22) \\
& +\sum_{m=1}^{\infty}\left(C_{i, m} f_{m}(r)-G_{i, m} r^{\frac{m \pi}{c}}+F_{i, m} r^{2}\right) \cos \left(\frac{m \pi}{c}\left(\theta-\alpha_{i}+\frac{c}{2}\right)\right) \\
& f_{m}(r)=r^{-\frac{m \pi}{c}}+\frac{r_{4}^{-\frac{m \pi}{c}} r^{\frac{m \pi}{c}}}{r_{4}^{\frac{m \pi}{c}}}, G_{i, m}=\frac{2 F_{i, m} r_{4}^{2} c}{r_{4}^{\frac{m \pi}{c}} m \pi}
\end{aligned}
$$

where $\alpha_{i}$ is the angular position of the ith stator slot and $c$ the slot opening in radian.

There are only interface conditions at $R_{m}$ and $R_{s}$ as:

$$
\begin{aligned}
& \operatorname{AII}_{j}\left(R_{m}, \theta\right)=\operatorname{AzI}\left(R_{m}, \theta\right) \\
& \operatorname{HIIt}_{j}\left(R_{m}, \theta\right)=\operatorname{HIt}\left(R_{m}, \theta\right) \\
& \operatorname{AzIII}_{i}\left(R_{s}, \theta\right)=\operatorname{AzI}\left(R_{s}, \theta\right) \\
& \operatorname{HIIIt}_{i}\left(R_{s}, \theta\right)=\operatorname{HIt}\left(R_{s}, \theta\right)
\end{aligned}
$$

The above boundary equalities deals with different subdomain frequencies therefore Fourier series expansions are necessary.

From (23), we have 


$$
\begin{aligned}
& A 5_{j, 0}=\frac{1}{a} \int_{g_{j}-\frac{a}{2}}^{g_{j}+\frac{a}{2}} A z I\left(R_{m}, \theta\right) d \theta \\
& A 5_{j, m} f_{m}\left(R_{m}\right)= \\
& \frac{2}{a} \int_{g_{j}-\frac{a}{2}}^{g_{j}+\frac{a}{2}} A z I\left(R_{m}, \theta\right) \cos \left(\frac{m \pi}{a}\left(\theta-g_{j}+\frac{a}{2}\right)\right) d \theta \\
& \left(\frac{n}{\mu_{0}}\right)\left(-A 1_{n} R_{m}^{n-1}+A 2_{n} R_{m}^{-n-1}\right)= \\
& \frac{1}{\pi} \sum_{j=1}^{N_{r}} \int_{g_{j}-\frac{a}{2}}^{g_{j}+\frac{a}{2}} H I I t_{j}\left(R_{m}, \theta\right) \sin (n \theta) d \theta \\
& \left(\frac{n}{\mu_{0}}\right)\left(-A 3_{n} R_{m}^{n-1}+A 4_{n} R_{m}^{-n-1}\right)= \\
& \frac{1}{\pi} \sum_{j=1}^{N_{r}} \int_{g_{j}-\frac{a}{2}}^{g_{j}+\frac{a}{2}} H I I t_{j}\left(R_{m}, \theta\right) \cos (n \theta) d \theta
\end{aligned}
$$

From (25), we have

$C_{i, 0}+\frac{1}{2} \mu_{0} J_{i, 0} r_{4}^{2} \ln \left(R_{s}\right)-\frac{1}{4} \mu_{0} J_{i, 0} R_{s}^{2}=$

$\frac{1}{c} \int_{\alpha_{i}-\frac{c}{2}}^{\alpha_{i}+\frac{c}{2}} A z I\left(R_{s}, \theta\right) d \theta$

$C_{i, m} f_{m}\left(R_{s}\right)-G_{i, m} R_{s}^{\frac{m \pi}{c}}+F_{i, m} R_{s}^{2}=$

$\frac{2}{c} \int_{\alpha_{i}-\frac{c}{2}}^{\alpha_{i}+\frac{c}{2}} A z I\left(R_{s}, \theta\right) \cos \left(\frac{m \pi}{c}\left(\theta-\alpha_{i}+\frac{c}{2}\right)\right) d \theta$

From (26), we have

$$
\begin{aligned}
& \left(\frac{n}{\mu_{0}}\right)\left(-A 1_{n} R_{s}^{n-1}+A 2_{n} R_{s}^{-n-1}\right)= \\
& \frac{1}{\pi} \sum_{i=1}^{N_{s}} \int_{\alpha_{i}-\frac{c}{2}}^{\alpha_{i}+\frac{c}{2}} H I I I t_{i}\left(R_{s}, \theta\right) \sin (n \theta) d \theta \\
& \left(\frac{n}{\mu_{0}}\right)\left(-A 3_{n} R_{s}^{n-1}+A 4_{n} R_{s}^{-n-1}\right)=
\end{aligned}
$$

$\frac{1}{\pi} \sum_{i=1}^{N_{s}} \int_{\alpha_{i}-\frac{c}{2}}^{\alpha_{i}+\frac{c}{2}} H I I I t_{i}\left(R_{s}, \theta\right) \cos (n \theta) d \theta$

The system of 8 equations (27) to (34) permits to determine the coefficients of the vector potentials in the 3 regions (11 subdomains) of internal rotor SRM.

\section{B. $6 / 4$ EE-FSM}

The internal rotor electrically-excited 6/4 FSM (Fig. 7) has 17 subdomains. In the air gap and rotor slots subdomains, the general forms of vector potentials are (20) and (21).

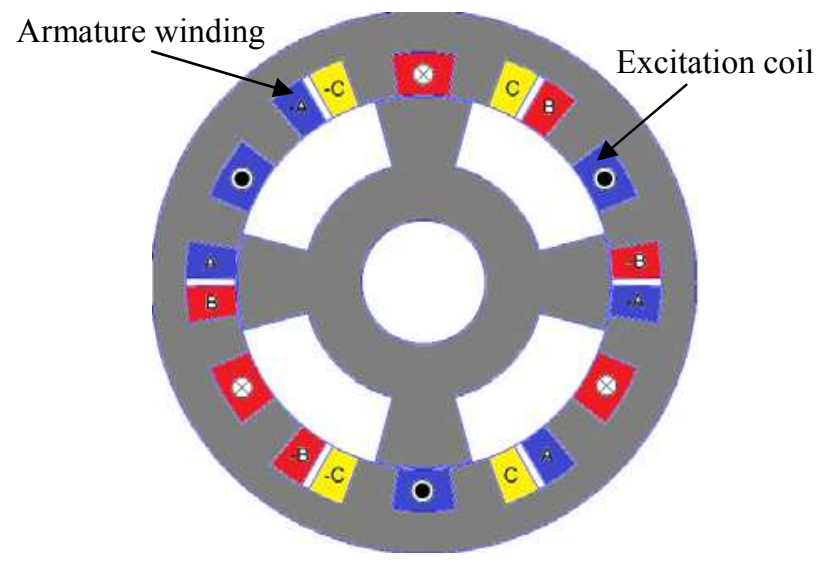

Fig. 7. Studied 6/4 internal rotor EE-FSM.

In the excitation coil region, general form of vector potential in the 6 subdomains is given by equation (4) as

$$
\begin{aligned}
& A z I V_{k}(r, \theta)=A 6_{k, 0}+\frac{1}{2} \mu_{0} J_{k} r_{3}^{2} \ln (r)-\frac{1}{4} \mu_{0} J_{k} r^{2} \\
& +\sum_{m=1}^{\infty} A 6_{k, m} f_{m}(r) \cos \left(\frac{m \pi}{d}\left(\theta-\beta_{k}+\frac{d}{2}\right)\right) \\
& f_{m}(r)=r^{-\frac{m \pi}{d}}+\frac{r_{3}^{-\frac{m \pi}{d}} r^{\frac{m \pi}{d}}}{r_{3}^{\frac{m \pi}{d}}}
\end{aligned}
$$

where $\beta_{k}$ is the angular position of the kth stator slot excitation coil and $d$ the slot opening in radian.

Equations (27)-(32) issued from interfaces conditions (23)(25) are the same. Of course, rotor slots and air gap subdomains for electrically-excited SFM are identical to SRM. The interface condition (26) is modified as

$$
\operatorname{HIt}\left(R_{s}, \theta\right)=\operatorname{HIIIt}_{i}\left(R_{s}, \theta\right)+\operatorname{HIVt}_{k}\left(R_{s}, \theta\right)
$$

And adding

$$
A z I V_{k}\left(R_{s}, \theta\right)=\operatorname{AzI}\left(R_{s}, \theta\right)
$$

From (36), we have

$$
\left(\frac{n}{\mu_{0}}\right)\left(-A 1_{n} R_{s}^{n-1}+A 2_{n} R_{s}^{-n-1}\right)=
$$




$$
\begin{aligned}
& \frac{1}{\pi} \sum_{i=1}^{N_{s}} \int_{\alpha_{i}-\frac{c}{2}}^{\alpha_{i}+\frac{c}{2}} H I I t_{i}\left(R_{s}, \theta\right) \sin (n \theta) d \theta+ \\
& \frac{1}{\pi} \sum_{k=1}^{N_{s}} \int_{\beta_{k}-\frac{d}{2}}^{\beta_{k}+\frac{d}{2}} H I V t_{k}\left(R_{s}, \theta\right) \sin (n \theta) d \theta \\
& \left(\frac{n}{\mu_{0}}\right)\left(-A 3_{n} R_{s}^{n-1}+A 4_{n} R_{s}^{-n-1}\right)= \\
& \frac{1}{\pi} \sum_{i=1}^{N_{s}} \int_{\alpha_{i}-\frac{c}{2}}^{\alpha_{i}+\frac{c}{2}} H I I I t_{i}\left(R_{s}, \theta\right) \cos (n \theta) d \theta+ \\
& \frac{1}{\pi} \sum_{k=1}^{N_{s}} \int_{\beta_{k}-\frac{d}{2}}^{\beta_{k}+\frac{d}{2}} H I V t_{k}\left(R_{s}, \theta\right) \cos (n \theta) d \theta
\end{aligned}
$$

From (37), we have

$A 6_{k, 0}+\frac{1}{2} \mu_{0} J_{k} r_{3}^{2} \ln \left(R_{s}\right)-\frac{1}{4} \mu_{0} J_{k} R_{s}^{2}=$

$$
\frac{1}{d} \int_{\beta_{k}-\frac{d}{2}}^{\beta_{k}+\frac{d}{2}} A z I\left(R_{s}, \theta\right) d \theta
$$

$$
A 6_{k, m} f_{m}\left(R_{s}\right)=
$$

$\frac{2}{d} \int_{\beta_{k}-\frac{d}{2}}^{\beta_{k}+\frac{d}{2}} A z I\left(R_{s}, \theta\right) \cos \left(\frac{m \pi}{d}\left(\theta-\beta_{k}+\frac{d}{2}\right)\right) d \theta$

The system of 10 equations (27) to (32) and (38) to (41) permits to determine the coefficients of the vector potentials in the 4 regions (17 subdomains) of internal rotor electricallyexcited FSM.

\section{6/4 PM-FSM}

Internal rotor permanent magnet-excited 6/4 FSM (Fig. 8) has 18 subdomains. In the air gap and rotor slots subdomains, the general forms of vector potentials are (20) and (21).

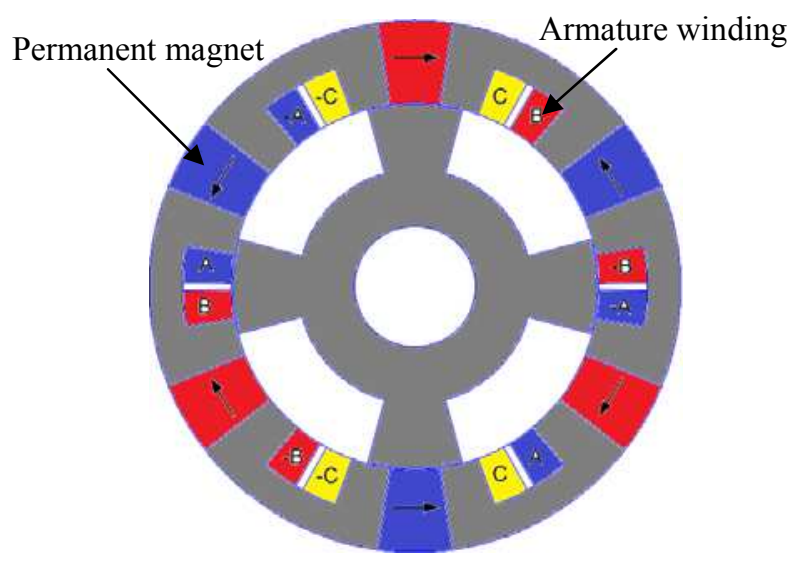

Fig. 8. Studied 6/4 internal rotor PM-FSM.

In the permanent magnet excitation region, vector potential has the general form of equation (10) as

$$
\begin{aligned}
& A z I V_{k}(r, \theta)=A 6_{k, 0}+A 7_{k, 0} \ln (r)-\mu_{0} M_{k} r \\
& +\sum_{m=1}^{\infty}\left(A 6_{k, m} r^{-\frac{m \pi}{d}}+A 7_{k, m} r^{\frac{m \pi}{d}}\right) \cos \left(\frac{m \pi}{d}\left(\theta-\beta_{k}+\frac{d}{2}\right)\right)
\end{aligned}
$$

where $\beta_{k}$ is the angular position of the $k$ th permanent magnet and $d$ the PM opening in radian.

The general form of vector potential of the outside machine region is given by equation (18) as

$$
A z V(r, \theta)=\sum_{n=1}^{\infty} A 8_{n} r^{-n} \sin (n \theta)+A 9_{n} r^{-n} \cos (n \theta)
$$

Equations (27)-(32) issued from interfaces conditions (23)(25) are not modified. However, the development of interface condition (26) is modified as

$$
\left(\frac{n}{\mu_{0}}\right)\left(-A 1_{n} R_{s}^{n-1}+A 2_{n} R_{s}^{-n-1}\right)=
$$

$\frac{1}{\pi} \sum_{i=1}^{N_{s}} \int_{\alpha_{i}-\frac{c}{2}}^{\alpha_{i}+\frac{c}{2}}$ HIIIt $_{i}\left(R_{s}, \theta\right) \sin (n \theta) d \theta+$

$\frac{1}{\pi} \sum_{k=1}^{N_{s}} \int_{\beta_{k}-\frac{d}{2}}^{\beta_{k}+\frac{d}{2}} H I V t_{k}\left(R_{s}, \theta\right) \sin (n \theta) d \theta$

$\left(\frac{n}{\mu_{0}}\right)\left(-A 3_{n} R_{s}^{n-1}+A 4_{n} R_{s}^{-n-1}\right)=$

$\frac{1}{\pi} \sum_{i=1}^{N_{s}} \int_{\alpha_{i}-\frac{c}{2}}^{\alpha_{i}+\frac{c}{2}}$ HIII $_{i}\left(R_{s}, \theta\right) \cos (n \theta) d \theta+$

$\frac{1}{\pi} \sum_{k=1}^{N_{s}} \int_{\beta_{k}-\frac{d}{2}}^{\beta_{k}+\frac{d}{2}} H I V t_{k}\left(R_{s}, \theta\right) \cos (n \theta) d \theta$ 
And adding

$$
\begin{aligned}
& A z I V_{k}\left(R_{s}, \theta\right)=A z I\left(R_{s}, \theta\right) \\
& A z I V_{k}\left(R_{\text {ext }}, \theta\right)=A z V\left(R_{\text {ext }}, \theta\right) \\
& H I V t_{k}\left(R_{\text {ext }}, \theta\right)=H V t\left(R_{\text {ext }}, \theta\right)
\end{aligned}
$$

From (46), we have

$A 6_{k, 0}+A 7_{k, 0} \ln \left(R_{s}\right)-\mu_{0} M_{k} R_{s}=$

$\frac{1}{d} \int_{\beta_{k}-\frac{d}{2}}^{\beta_{k}+\frac{d}{2}} A z I\left(R_{s}, \theta\right) d \theta$

$A 6_{k, m} R_{s}^{-\frac{m \pi}{d}}+A 7_{k, m} R_{s}^{\frac{m \pi}{d}}=$

$\frac{2}{d} \int_{\beta_{k}-\frac{d}{2}}^{\beta_{k}+\frac{d}{2}} A z I\left(R_{s}, \theta\right) \cos \left(\frac{m \pi}{d}\left(\theta-\beta_{k}+\frac{d}{2}\right)\right) d \theta$

From (47), we have

$$
\begin{aligned}
& A 6_{k, 0}+A 7_{k, 0} \ln \left(R_{e x t}\right)-\mu_{0} M_{k} R_{e x t}= \\
& \frac{1}{d} \int_{\beta_{k}-\frac{d}{2}}^{\beta_{k}+\frac{d}{2}} A z V\left(R_{\text {ext }}, \theta\right) d \theta \\
& A 6_{k, m} R_{\text {ext }}^{-\frac{m \pi}{d}}+A 7_{k, m} R_{\text {ext }}^{\frac{m \pi}{d}}= \\
& \frac{2}{d} \int_{\beta_{k}-\frac{d}{2}}^{\beta_{k}+\frac{d}{2}} A z V\left(R_{\text {ext }}, \theta\right) \cos \left(\frac{m \pi}{d}\left(\theta-\beta_{k}+\frac{d}{2}\right)\right) d \theta
\end{aligned}
$$

From (48), we have

$$
\left(\frac{n}{\mu_{0}}\right)\left(A 8_{n} R_{e x t}^{-n-1}\right)=
$$

$\frac{1}{\pi} \sum_{k=1}^{N_{s}} \int_{\beta_{k}-\frac{d}{2}}^{\beta_{k}+\frac{d}{2}} H I V t_{k}\left(R_{e x t}, \theta\right) \sin (n \theta) d \theta$

$\left(\frac{n}{\mu_{0}}\right)\left(A 9_{n} R_{e x t}^{-n-1}\right)=$

$$
\frac{1}{\pi} \sum_{k=1}^{N_{s}} \int_{\beta_{k}-\frac{d}{2}}^{\beta_{k}+\frac{d}{2}} H I V t_{k}\left(R_{\text {ext }}, \theta\right) \cos (n \theta) d \theta
$$

The system of 14 equations (27) to (32) and (44) to (45) and (49) to (54) permits to determine the coefficients of the vector potentials in the 5 regions (18 subdomains) of internal rotor permanent magnet-excited FSM. It is important to note here that it is not necessary to set the divergence of the magnetic flux density around the stator to zero to solve the unknown coefficients $A 7_{k, 0}$ of region IV as it is done in [12].

\section{Topology1: 6/4 HE-FSM}

The internal rotor hybrid-excited FSM (Fig. 9) has 6 regions and 24 subdomains. The Ns permanent magnet subdomains of Fig. 8 are replaced with $2 * N s$ subdomains combining both permanent magnet and single layer excitation coils in the slots.

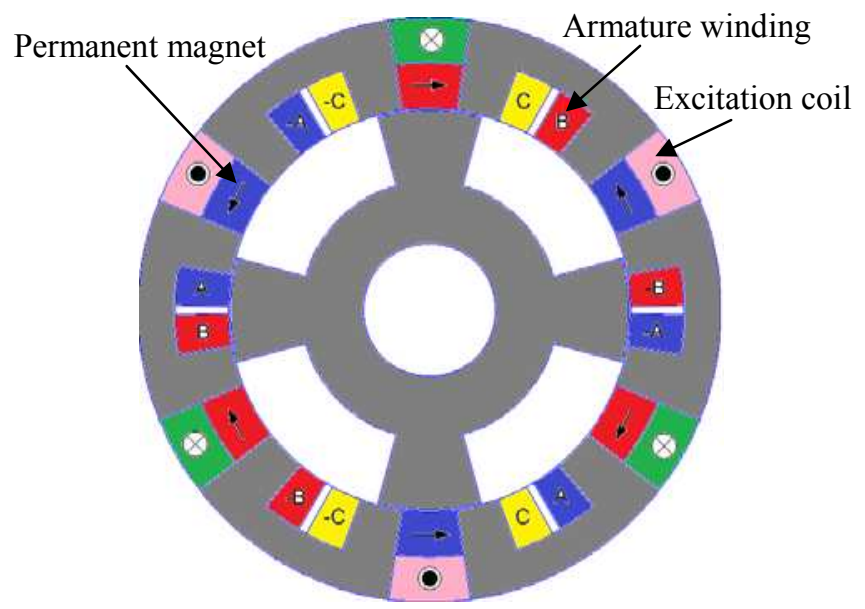

Fig. 9. Studied 6/4 internal rotor HE-FSM.

General forms of vector potentials in rotor slots, air gap, armature slots, permanent magnet and outside machine are given by (20)-(22) and (42)-(43). In the excitation coil (single layer winding), the general form of vector potential is given by equation (5) as

$$
\begin{aligned}
& A z V I_{k}(r, \theta)=A 10_{k, 0}+A 11_{k, 0} \ln (r)-\frac{1}{4} \mu_{0} J_{k} r^{2} \\
& +\sum_{l=1}^{\infty}\left(A 10_{k, l} r^{-\frac{l \pi}{d}}+A 11_{k, l} r^{\frac{l \pi}{d}}\right) \cos \left(\frac{l \pi}{d}\left(\theta-\beta_{k}+\frac{d}{2}\right)\right)
\end{aligned}
$$

Interfaces conditions (23)-(25) and (36)-(37) are valid with adding

$$
\begin{aligned}
& A z V I_{k}\left(R_{e x t}, \theta\right)=A z V\left(R_{\text {ext }}, \theta\right) \\
& \operatorname{HVIt}_{k}\left(R_{\text {ext }}, \theta\right)=\operatorname{HVt}\left(R_{\text {ext }}, \theta\right) \\
& A z V I_{k}\left(r_{3}, \theta\right)=A z I V_{k}\left(r_{3}, \theta\right) \\
& \operatorname{HVIt}_{k}\left(r_{3}, \theta\right)=\operatorname{HIVt}_{k}\left(r_{3}, \theta\right)
\end{aligned}
$$

From (56), we have

$$
\begin{gathered}
A 10_{k, 0}+A 11_{k, 0} \ln \left(R_{e x t}\right)-\frac{1}{4} \mu_{0} J_{k} R_{\text {ext }}^{2}= \\
\frac{1}{d} \int_{\beta_{k}-\frac{d}{2}}^{\beta_{k}+\frac{d}{2}} A z V(R, \theta) d \theta \\
A 10_{k, l} R_{\text {ext }}^{-\frac{l \pi}{d}}+A 11_{k, l} R_{\text {ext }}^{\frac{l \pi}{d}}=
\end{gathered}
$$




$$
\frac{2}{d} \int_{\beta_{k}-\frac{d}{2}}^{\beta_{k}+\frac{d}{2}} A z V(R, \theta) \cos \left(\frac{l \pi}{d}\left(\theta-\beta_{k}+\frac{d}{2}\right)\right) d \theta
$$

From (57), we have

$\left(\frac{n}{\mu_{0}}\right)\left(A 8_{n} R_{e x t}^{-n-1}\right)=$

$\frac{1}{\pi} \sum_{k=1}^{N_{s}} \int_{\beta_{k}-\frac{d}{2}}^{\beta_{k}+\frac{d}{2}} H V I t_{k}\left(R_{e x t}, \theta\right) \sin (n \theta) d \theta$

$\left(\frac{n}{\mu_{0}}\right)\left(A 9_{n} R_{e x t}^{-n-1}\right)=$

$\frac{1}{\pi} \sum_{k=1}^{N_{s}} \int_{\beta_{k}-\frac{d}{2}}^{\beta_{k}+\frac{d}{2}} H V I t_{k}\left(R_{\text {ext }}, \theta\right) \cos (n \theta) d \theta$

From (58), we have

$A 6_{k, 0}+A 7_{k, 0} \ln \left(r_{3}\right)-\mu_{0} M_{k} r_{3}=$

$\frac{1}{d} \int_{\beta_{k}-\frac{d}{2}}^{\beta_{k}+\frac{d}{2}} A z V I_{k}\left(r_{3}, \theta\right) d \theta$

$A 6_{k, m} r_{3}^{-\frac{m \pi}{d}}+A 7_{k, m} r_{3}^{\frac{m \pi}{d}}=$

$\frac{2}{d} \int_{\beta_{k}-\frac{d}{2}}^{\beta_{k}+\frac{d}{2}} A z V I_{k}\left(r_{3}, \theta\right) \cos \left(\frac{m \pi}{d}\left(\theta-\beta_{k}+\frac{d}{2}\right)\right) d \theta$

From (59), we have

$\left(\frac{1}{\mu_{0}}\right)\left(-\frac{A 11_{k, 0}}{r_{3}}+\frac{1}{2} \mu_{0} J_{k} r_{3}\right)=-\frac{A 7_{k, 0}}{\mu_{0} \mu_{r} r_{3}}$

$\left(\frac{l \pi}{d \mu_{0}}\right)\left(A 10_{k, l} r_{3}^{-\frac{l \pi}{d}-1}-A 11_{k, l} r_{3}^{\frac{l \pi}{d}-1}\right)=0$

The system of 18 equations (27) to (32) and (38) to (41) and (60) to (67) permits to determine the coefficients of the vector potentials in the 6 regions ( 24 subdomains) of internal rotor hybrid-excited FSM.

\section{E. Topology2: 12/10 HE-FSM}

Internal rotor HE-FSM (Fig. 10) has 6 regions and 36 subdomains. The study of this topology use general vector potential forms of equations (20)-(21) and (42)-(43) which are the same as PM-FSM. Equation (35) is modified as

$$
A z V I_{k}(r, \theta)=A 10_{k, 0}+\frac{1}{2} \mu_{0} J_{k} r_{3}^{2} \ln (r)-\frac{1}{4} \mu_{0} J_{k} r^{2}
$$

$$
\begin{aligned}
& +\sum_{m=1}^{\infty} A 10_{k, m} f_{m}(r) \cos \left(\frac{m \pi}{d_{c}}\left(\theta-\lambda_{k}+\frac{d_{c}}{2}\right)\right) \\
& f_{m}(r)=r^{-\frac{m \pi}{d c}}+\frac{r_{3}^{-\frac{m \pi}{d c}} r^{\frac{m \pi}{d c}}}{r_{3}^{\frac{m \pi}{d c}}}
\end{aligned}
$$

where $\lambda_{k}$ is the angular position of the $k t h$ stator excitation slot and $d_{c}$ the slot opening in radian.

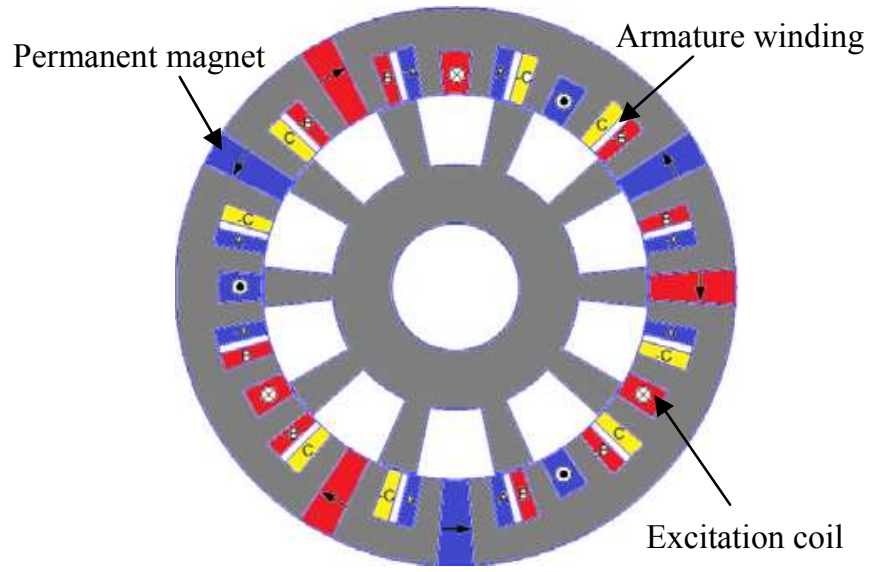

Fig. 10. Studied 12/10 internal rotor HE-FSM.

Interfaces conditions (23)-(25), (46)-(48) are the same with modifying (26) as

$\operatorname{HIt}\left(R_{s}, \theta\right)=\operatorname{HIIIt}_{i}\left(R_{s}, \theta\right)+\operatorname{HIVt}_{k}\left(R_{s}, \theta\right)+\operatorname{HVIt}_{k}\left(R_{s}, \theta\right)$

And adding

$A z V I_{k}\left(R_{s}, \theta\right)=A z I\left(R_{s}, \theta\right)$

From (69), we have

$\left(\frac{n}{\mu_{0}}\right)\left(-A 1_{n} R_{s}^{n-1}+A 2_{n} R_{s}^{-n-1}\right)=$

$\frac{1}{\pi} \sum_{i=1}^{N_{s}} \int_{\alpha_{i}-\frac{c}{2}}^{\alpha_{i}+\frac{c}{2}} \operatorname{HIIIt}_{i}\left(R_{s}, \theta\right) \sin (n \theta) d \theta+$

$\frac{1}{\pi} \sum_{k=1}^{\frac{N_{s}}{2}} \int_{\beta_{k}-\frac{d}{2}}^{\beta_{k}+\frac{d}{2}} H I V t_{k}\left(R_{s}, \theta\right) \sin (n \theta) d \theta$

$\frac{1}{\pi} \sum_{k=1}^{\frac{N_{s}}{2}} \int_{\lambda_{k}-\frac{d_{c}}{2}}^{\lambda_{k}+\frac{d_{c}}{2}} H V I t_{k}\left(R_{s}, \theta\right) \sin (n \theta) d \theta$

$\left(\frac{n}{\mu_{0}}\right)\left(-A 3_{n} R_{s}^{n-1}+A 4_{n} R_{s}^{-n-1}\right)=$ 


$$
\begin{aligned}
& \frac{1}{\pi} \sum_{i=1}^{N_{s}} \int_{\alpha_{i}-\frac{c}{2}}^{\alpha_{i}+\frac{c}{2}} H I I I t_{i}\left(R_{s}, \theta\right) \cos (n \theta) d \theta+ \\
& \frac{1}{\pi} \sum_{k=1}^{\frac{N_{s}}{2}} \int_{\beta_{k}-\frac{d}{2}}^{\beta_{k}+\frac{d}{2}} H I V t_{k}\left(R_{s}, \theta\right) \cos (n \theta) d \theta \\
& \frac{1}{\pi} \sum_{k=1}^{\frac{N_{s}}{2}} \int_{\lambda_{k}-\frac{d_{c}}{2}}^{\lambda_{k}+\frac{d_{c}}{2}} H V I t_{k}\left(R_{s}, \theta\right) \cos (n \theta) d \theta
\end{aligned}
$$

From (70), we have

$$
\begin{aligned}
& A 10_{k, 0}+\frac{1}{2} \mu_{0} J_{k} r_{3}^{2} \ln \left(R_{s}\right)-\frac{1}{4} \mu_{0} J_{k} R_{s}^{2}= \\
& \frac{1}{d_{c}} \int_{\lambda_{k}-\frac{d_{c}}{2}}^{\lambda_{k}+\frac{d_{c}}{2}} A z I\left(R_{s}, \theta\right) d \theta \\
& A 10_{k, m} f_{m}\left(R_{s}\right)= \\
& \frac{2}{d_{c}} \int_{\lambda_{k}-\frac{d_{c}}{2}}^{\lambda_{k}+\frac{d_{c}}{2}} A z I\left(R_{s}, \theta\right) \cos \left(\frac{m \pi}{d_{c}}\left(\theta-\lambda_{k}+\frac{d_{c}}{2}\right)\right) d \theta
\end{aligned}
$$

The system of 16 equations (27)-(32) and (49)-(54) and (71)(74) permits to determine the coefficients of the vector potentials in the 6 regions (36 subdomains) of internal rotor HE-FSM.

\section{RESUlts AND VALIDATION}

The developed general formulation of subdomain model is used to determine the magnetic field distribution in the middle of the air gap of FSM. The main dimensions and parameters of the studied machines are given in Table I. Then, analytical results are verified by finite element method (FEM) [24].

For 6/4 switched flux machines with double layer winding, armature current density in slots is defined by two matrix connection between the 3 phases current and the stator slots as

$$
\begin{aligned}
C 1 & =\left[\begin{array}{cccccc}
-1 & 0 & 0 & 1 & 0 & 0 \\
0 & 1 & 0 & 0 & -1 & 0 \\
0 & 0 & -1 & 0 & 0 & 1
\end{array}\right] \\
C 2 & =\left[\begin{array}{cccccc}
0 & 0 & -1 & 0 & 0 & 1 \\
-1 & 0 & 0 & 1 & 0 & 0 \\
0 & 1 & 0 & 0 & -1 & 0
\end{array}\right]
\end{aligned}
$$

For 12/10 FSM with double layer winding, armature current density in slots is defined by two matrix connections between the 3 phases current and the stator slots as

$$
\begin{aligned}
C 1 & =\left[\begin{array}{cccccccccccc}
-1 & 0 & 0 & -1 & 0 & 0 & -1 & 0 & 0 & -1 & 0 & 0 \\
0 & -1 & 0 & 0 & -1 & 0 & 0 & -1 & 0 & 0 & -1 & 0 \\
0 & 0 & -1 & 0 & 0 & -1 & 0 & 0 & -1 & 0 & 0 & -1
\end{array}\right] \\
C 2 & =\left[\begin{array}{llllllllllll}
0 & 0 & 1 & 0 & 0 & 1 & 0 & 0 & 1 & 0 & 0 & 1 \\
1 & 0 & 0 & 1 & 0 & 0 & 1 & 0 & 0 & 1 & 0 & 0 \\
0 & 1 & 0 & 0 & 1 & 0 & 0 & 1 & 0 & 0 & 1 & 0
\end{array}\right]
\end{aligned}
$$

Stator current densities in slots for double layer armature winding are defined as

$$
\begin{aligned}
& J_{i, 1}=\frac{N_{c}}{S} C 1^{T}\left[\begin{array}{lll}
I_{a} & I_{b} & I_{c}
\end{array}\right] \\
& J_{i, 2}=\frac{N_{c}}{S} C 2^{T}\left[\begin{array}{lll}
I_{a} & I_{b} & I_{c}
\end{array}\right]
\end{aligned}
$$

where $S$ is the area of slot coil region and $N_{c}$ the number of conductors in slot coil region.

Single layer excitation coils current densities for $6 / 4$ and $12 / 10$ switched flux machines are defined as

$$
J=\frac{N_{f} I_{f}}{S_{f}}\left[\begin{array}{llllll}
-1 & 1 & -1 & 1 & -1 & 1
\end{array}\right]
$$

where $N_{f}$ is the number of conductors in slot, $I_{f}$ the DC excitation current and $S_{f}$ the surface of stator slot.

For slotted structures, computation of flux linkage with the method of winding function theory is not suitable. The method based on Stokes theorem using the vector potential in stator slots is used. First, we determine at a given rotor position $\theta_{r}$, the flux over each coil of slot $i$ of cross section $S$. We have supposed that the current is uniformly distributed over the slot coil area, so the vector potential can be averaged over the slot coil area to represent the coil.

For the coil with a current density $J_{i, 1}$ (Fig. 2), we obtain:

$$
\varphi_{1, i}=\frac{L u}{S} \int_{\alpha_{i}-\frac{c}{2}}^{\alpha_{i}-\frac{c}{2}+d} \int_{R_{s}}^{r_{4}} A I I I_{i}(r, \theta) r d r d \theta
$$

For the coil with a current density $J_{i, 2}$ (Fig. 2) we have

$$
\varphi_{2, i}=\frac{L u}{S} \int_{\alpha_{i}+\frac{c}{2}-d}^{\alpha_{i}+\frac{c}{2}} \int_{R_{s}}^{r_{4}} A I I_{i}(r, \theta) r d r d \theta
$$

where $S=\frac{d\left(r_{4}^{2}-R_{s}^{2}\right)}{2}$ is the surface of the stator slot coil (inner radius $R_{s}$ and outer radius $r_{4}$ ).

For the coil with current density $J_{i, 1}$, the phase flux linkage vector is given by

$$
\left[\begin{array}{l}
\psi 1_{a} \\
\psi 1_{b} \\
\psi 1_{c}
\end{array}\right]=N_{c} C 1^{\prime}\left[\begin{array}{lllll}
\varphi_{1,1} & \varphi_{1,2} & \ldots & \varphi_{1, Q_{s}-1} & \varphi_{1, Q_{s}}
\end{array}\right]
$$


For the coil with current density $J_{i, 2}$, the phase flux linkage vector is

$$
\left[\begin{array}{l}
\psi 2_{a} \\
\psi 2_{b} \\
\psi 2_{c}
\end{array}\right]=N_{c} C 2^{\prime}\left[\begin{array}{lllll}
\varphi_{2,1} & \varphi_{2,2} & \ldots & \varphi_{2, Q_{s}-1} & \varphi_{2, Q_{s}}
\end{array}\right]
$$

where $\mathrm{C}^{\prime}$ ' and $\mathrm{C} 2$ ' are the transpose of connecting matrix that represent the distribution of stator windings in the slots. The total flux linkage per phase is given by

$$
\left[\begin{array}{l}
\psi_{a} \\
\psi_{b} \\
\psi_{c}
\end{array}\right]=\left[\begin{array}{l}
\psi 1_{a} \\
\psi 1_{b} \\
\psi 1_{c}
\end{array}\right]+\left[\begin{array}{l}
\psi 2_{a} \\
\psi 2_{b} \\
\psi 2_{c}
\end{array}\right]
$$

The three phase back-EMF vector is calculated by

$$
\left[\begin{array}{c}
E_{a} \\
E_{b} \\
E_{c}
\end{array}\right]=\Omega \frac{d}{d \theta_{r}}\left[\begin{array}{l}
\psi_{a} \\
\psi_{b} \\
\psi_{c}
\end{array}\right]
$$

where $\Omega$ is the rotor angular speed.

TABLE I

PRINCIPAL PARAMETERS Of STUdiEd INTERNAL SWITCHED FluX MACHINES

\begin{tabular}{lcc}
\hline \hline Parameter & Symbol & $\begin{array}{c}\text { Value and } \\
\text { unit }\end{array}$ \\
\hline Magnet remanence (Ferrite) & $B_{r}$ & $0.4 \mathrm{~T}$ \\
Relative recoil permeability of magnet & $\mu_{r}$ & 1 \\
Number of conductors per stator slot & $N_{c}$ & 20 \\
Peak phase current & $I_{m}$ & $15 \mathrm{~A}$ \\
DC excitation current & $I_{f}$ & $20 \mathrm{~A}$ \\
Number of conductors per rotor slot & $N_{f}$ & 30 \\
Number of stator slots & $N_{s}$ & $6 / 12$ \\
Number of rotor poles & $N r$ & $4 / 10$ \\
Internal radius of rotor slot & $r_{l}$ & $58 \mathrm{~mm}$ \\
External radius of magnet & $r_{5}$ & $105 \mathrm{~mm}$ \\
Internal radius of stator slot & $r_{3}$ & $111.5 \mathrm{~mm}$ \\
External radius of stator slot & $r_{4}$ & $115.3 \mathrm{~mm}$ \\
Radius of the external stator surface & $R_{e x t}$ & $132 \mathrm{~mm}$ \\
Radius of the stator internal surface & $R_{s}$ & $91 \mathrm{~mm}$ \\
Radius of the rotor inner surface at the rotor & $R_{m}$ & $90.2 \mathrm{~mm}$ \\
surface & $g$ & $0.8 \mathrm{~mm}$ \\
Air-gap length & $L_{u}$ & $70 \mathrm{~mm}$ \\
Stack length & $R_{i}$ & $30 \mathrm{~mm}$ \\
Radius of the shaft & $c$ & $20^{\circ}$ \\
Stator slot opening width (6/4 FSM) & $c$ & $10^{\circ}$ \\
Stator slot opening width (16/10 FSM) & $d$ & $9{ }^{\circ}$ \\
Stator slot coil opening width (6/4 FSM) & $d$ & $44^{\circ}$ \\
Stator slot coil opening width (12/10 FSM) & $d$ & $16^{\circ}$ \\
Magnet opening (6/4 FSM) & $d$ & $2.5^{\circ}$ \\
Magnet opening (12/10 FSM) & $d_{c}$ & $2.5^{\circ}$ \\
Excitation stator slot opening (12/10 FSM) & $d$ & $16^{\circ}$ \\
Excitation stator slot opening (6/4 FSM) & $a$ & $60^{\circ}$ \\
Rotor slot opening (6/4 FSM) & $\Omega$ & $157 \mathrm{rd} / \mathrm{s}$ \\
Rotor speed & & \\
\hline \hline
\end{tabular}

Analytical calculation of magnetic field in the middle of air gap in all FSM topologies is done for 1 phase fed by a constant current. Figs. 11, 12, 14, 16 and 18 show a comparison between analytical and FEM radial and tangential flux densities results of internal rotor SRM, EE-FSM, PMFSM and HE-FSM. The results are in excellent agreement, which confirm the accuracy of the analytical subdomain model. To avoid many figures, the contribution of armature reaction current, excitation coil current and permanent magnet are given at the same time. Back-EMF waveforms due to excitation current, permanent magnet and hybrid excitation for EE-FSM, PM-FSM and HE-FSM respectivelly are shown in Figs. 13, 15, 17 and 19. The comparison between analytical and FEM methods shows an excellent agreement.

The computational time requirements for magnetic field calculation in studied FSM topologies with subdomain model and FEM are shown in Table II. Analytical calculation time for used number of harmonics $n, m$ and $1(200,80$ and 80$)$ is greater when the number of subdomains increases. FEM computational time increases also when the number of elements is higher for the same studied domain (surface). It is important to notice that when calculating cogging torque and electromagnetic torque with FEM, the number of elements given in Table II is not sufficient to get a good accuracy. However, the subdomain model is accurate without changing the number of harmonics and then computational time.

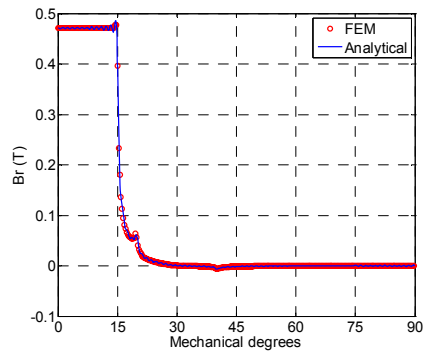

a)

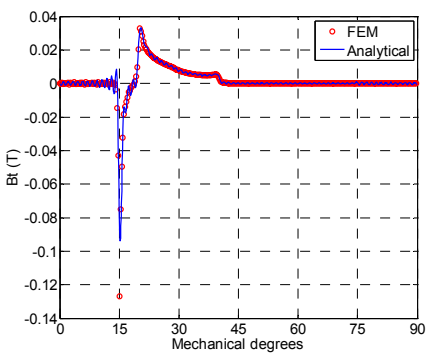

b)
Fig. 11. Radial (a) and tangential (b) flux density due to phase $A$ in internal rotor 6/4 SRM.

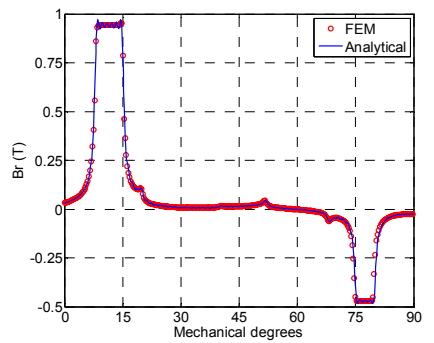

a)

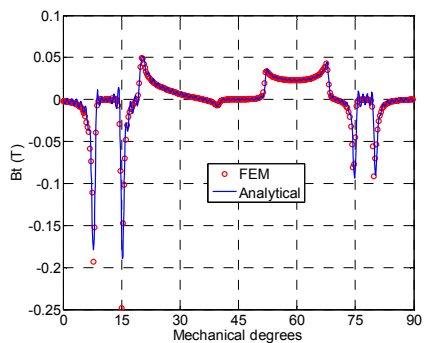

b)
Fig. 12. Radial (a) and tangential (b) flux density due to phase $A$ and excitation current in internal rotor 6/4 EE-FSM. 


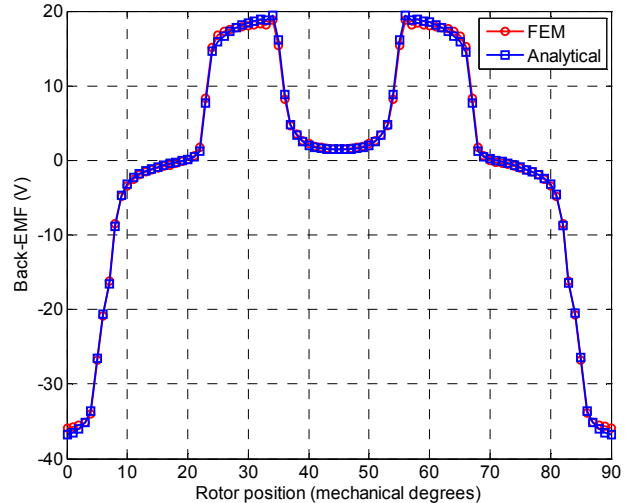

Fig. 13. Back-EMF due to excitation current in internal rotor 6/4 EE-FSM.

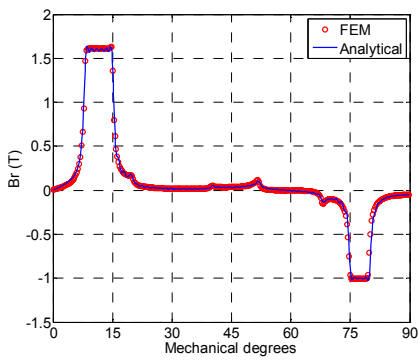

a)

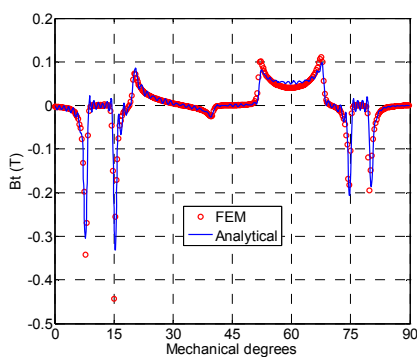

b)
Fig. 14. Radial (a) and tangential (b) flux density due to phase A and permanent magnet in internal rotor 6/4 PM-FSM.

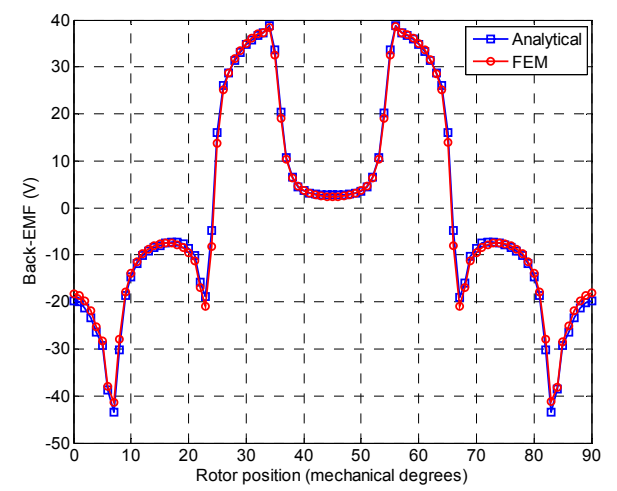

Fig. 15. Back-EMF due to permanent magnet in internal rotor 6/4 PM-FSM.
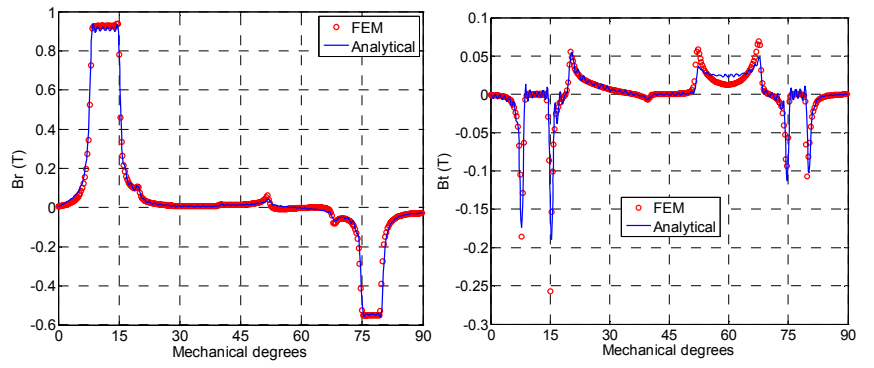

a)

b)

Fig. 16. Radial (a) and tangential (b) flux density due to phase A, excitation current and permanent magnet in internal rotor 6/4 HE-FSM (Topology 1).

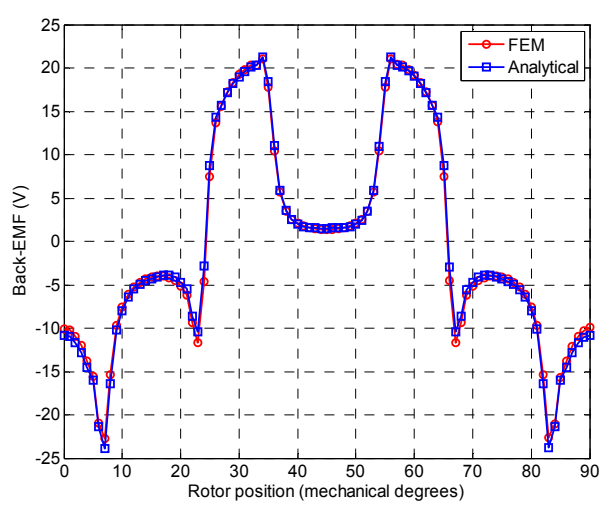

Fig. 17. Back-EMF due excitation current and permanent magnet in internal rotor 6/4 HE-FSM (Topology 1).

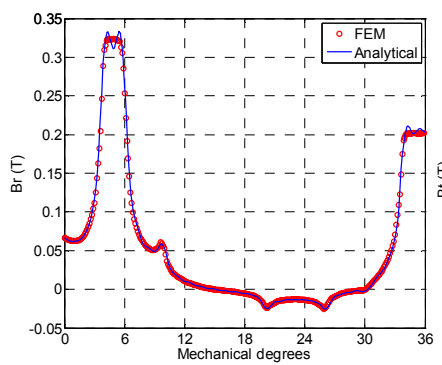

a)

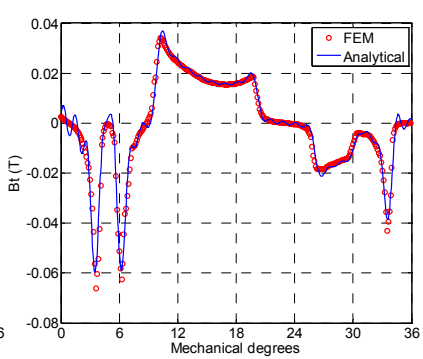

b)
Fig. 18. Radial (a) and tangential (b) flux density due to phase A and excitation current in internal rotor 12/10 HE-FSM (Topology 2).

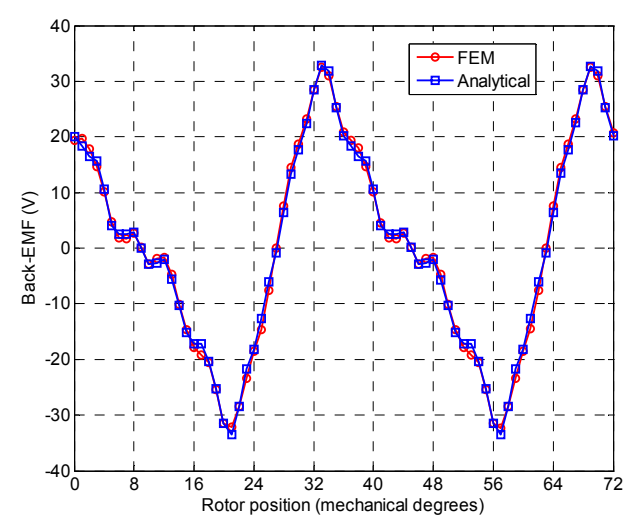

Fig. 19. Back-EMF due to excitation current and permanent magnet in internal rotor 12/10 HE-FSM (Topology 2).

TABLE II

Computational Time COMPaRison BetweEn Subdomain Model AND FEM 


\begin{tabular}{|l|c|c|c|}
\hline \multicolumn{1}{|c|}{ FSM topologies } & $\begin{array}{c}\text { Subdomain } \\
\text { model (s) }\end{array}$ & $\begin{array}{c}\text { FEM } \\
\text { (s) }\end{array}$ & $\begin{array}{c}\text { Mesh (nodes, } \\
\text { elements) }\end{array}$ \\
\hline 6/4 SRM & 7,44 & 32 & 111517,222169 \\
\hline 6/4 FE-FSM & 10,75 & 42,62 & 167840,334951 \\
\hline 6/4 PM-FSM & 15,43 & 40,3 & 191769,382816 \\
\hline 6/4 HE-FSM & 17 & 40,53 & 194499,388276 \\
\hline 12/10 HE-FSM & 32 & 49,3 & 193422,386122 \\
\hline
\end{tabular}

\section{CONCLUSION}

In this paper, we have proposed a general formulation of subdomain model for predicting magnetic field distribution in any number of stator slots, rotor poles and phases FSM topologies. The developed method can be compared to finite element method where each element is a subdomain and the form function of element the general form of the vector potential in a subdomain. As shown, many topologies of FSM can be analyzed with subdomain method as we can do with finite element method. The main drawback of subdomain method is that the soft magnetic material must be considered as linear or with infinite permeability. With the subdomain method, we can elaborate a general program that can predict magnetic field distribution and optimize many types of FSM. This general model can be extended to multiphase permanent magnet and wound machines with any number of stator slots and rotor poles taking into account rotor and stator tooth tips. Analytical results are in excellent agreement with the ones obtained by FEM.

\section{APPENDIX A}

The prediction of magnetic field distribution in external rotor SRM and FSM topologies is practically the same as internal rotor topologies. However, some modifications should be introduced for PM-FSM and HE-FSM. Common parameters of the different considered structures are detailed in Table III.

TABLE III

Principal Parameters Of StUdied EXTERnAL SWitched FluX Machines

\begin{tabular}{lcc}
\hline \hline Parameter & Symbol & $\begin{array}{c}\text { Value and } \\
\text { unit }\end{array}$ \\
\hline Internal radius of rotor slot & $r_{1}$ & $115.3 \mathrm{~mm}$ \\
External radius of magnet & $r_{5}$ & $58.3 \mathrm{~mm}$ \\
Internal radius of stator slot & $r_{3}$ & $61.8 \mathrm{~mm}$ \\
External radius of stator slot & $r_{4}$ & $58 \mathrm{~mm}$ \\
Radius of the external stator surface & $R_{e x t}$ & $132 \mathrm{~mm}$ \\
Radius of the stator internal surface & $R_{s}$ & $82.3 \mathrm{~mm}$ \\
Radius of the rotor inner surface at the rotor & $R_{m}$ & $83.1 \mathrm{~mm}$ \\
surface & $R_{i}$ & $30 \mathrm{~mm}$ \\
Radius of the shaft & & \\
\hline \hline
\end{tabular}

\section{A. 6/4 External Rotor SRM}

For external rotor SRM (Fig. 20), the same equations as internal rotor SRM are used. However, there is a numerical limitation for the harmonic $\mathrm{m}$ to be solved with adding a proper scaling of machine as explained in [19] and [20]. This numerical limitation can be also solved with changing the general form of vector potential in armature slots subdomains from (8) to (7) and adding a Dirichlet boundary condition at $r_{4}$. Radial and tangential flux densities are shown in Fig. 21, where a very good agreement between analytical model and FEM is obtained.

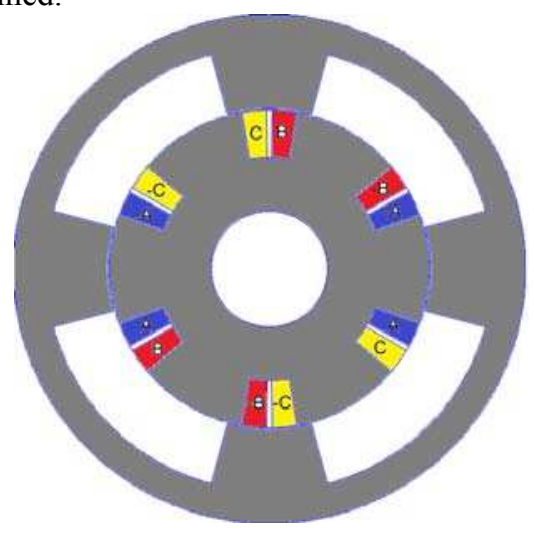

Fig. 20. Studied 6/4 external rotor SRM.

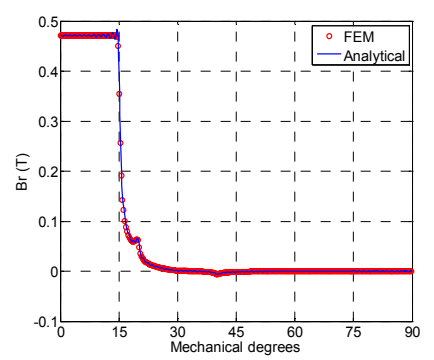

a)

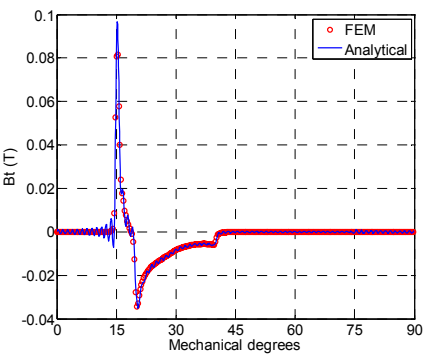

b)
Fig. 21. Radial (a) and tangential (b) flux density due to phase A only in external rotor 6/4 SRM.

\section{B. 6/4 External Rotor EE-FSM}

For external rotor EE-FSM (Fig. 22), the same equations as for internal rotor EE-FSM are used. Analytical results are in very good agreement with those obtained by FEM (Fig. 23).

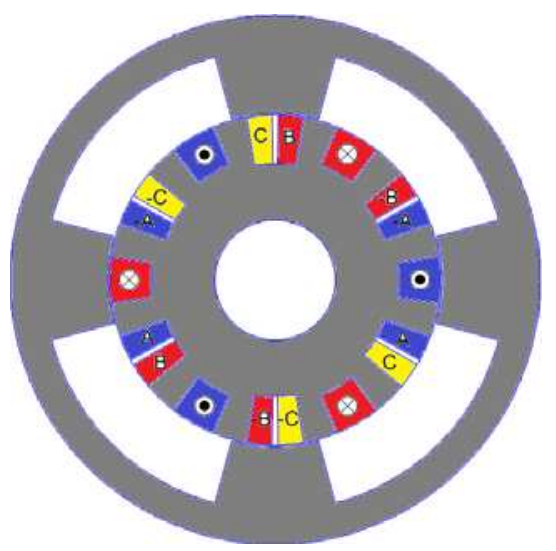

Fig. 22. Studied 6/4 external rotor EE-FSM. 


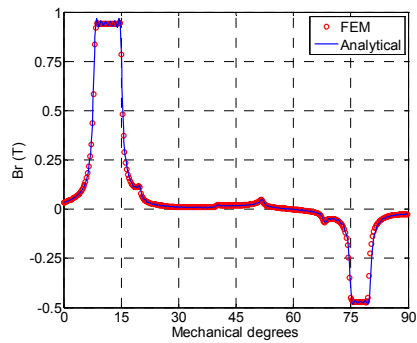

a)

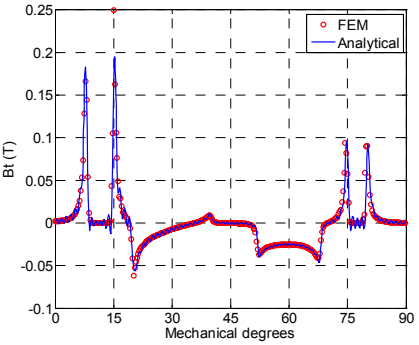

b)
Fig. 23. Radial (a) and tangential (b) flux density due to phase A and excitation current in external rotor 6/4 EE-FSM.

\section{6/4 External Rotor PM-FSM}

For external rotor PM-FSM (Fig. 24) which has been studied by FEM in [5], the outside machine region is replaced with the shaft region where the general form of vector potential is given by equation (19).

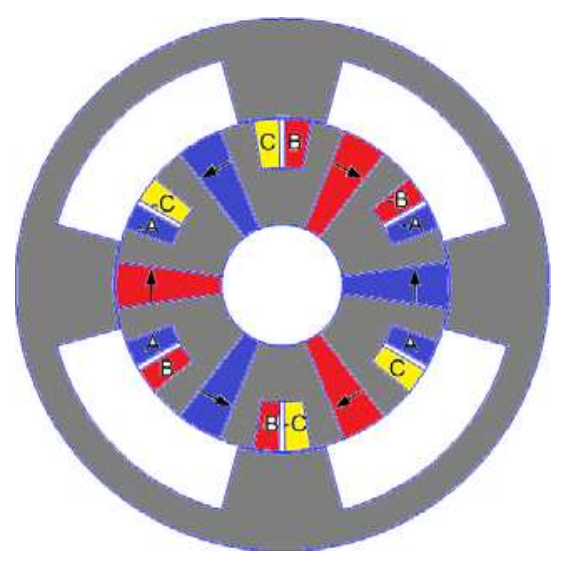

Fig. 24. Studied 6/4 external rotor PM-FSM.

The same development as for internal rotor PM-FSM can be done with introducing interfaces conditions. Radial and tangential flux densities comparison is shown in Fig. 25.

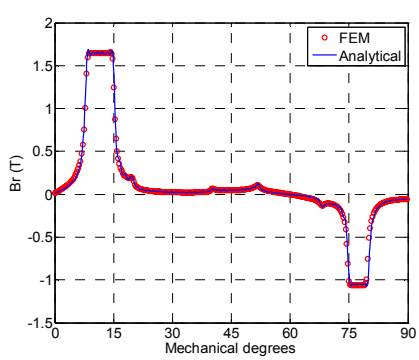

a)

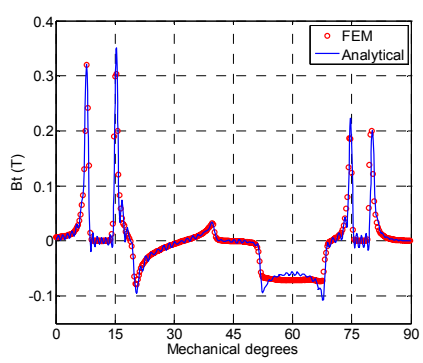

b)
Fig. 25. Radial (a) and tangential (b) flux density due to phase $A$ and permanent magnet in external rotor PM-FSM.

\section{Topology 1: External rotor 6/4 HE-FSM}

This structure (Fig. 26) uses the same equations for all subdomains as internal rotor HE-FSM, except for the shaft region which replaces outside machine region is given with (19). Radial and tangential flux densities due to phase A current, excitation current and permanent magnet are shown in Fig. 27.

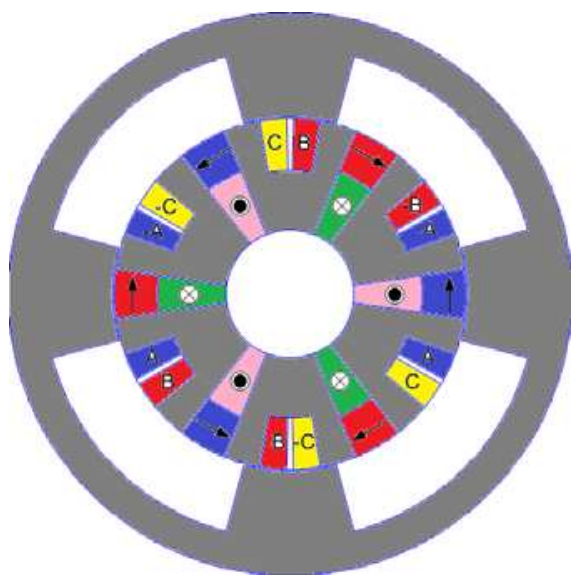

Fig. 26. Studied 6/4 external rotor HE-FSM (Topology 1).

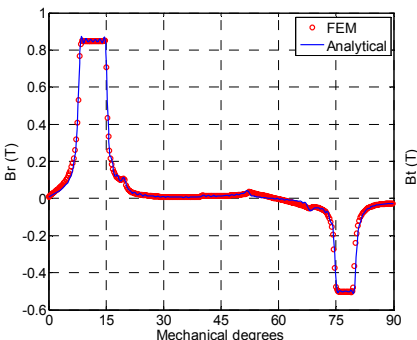

a)

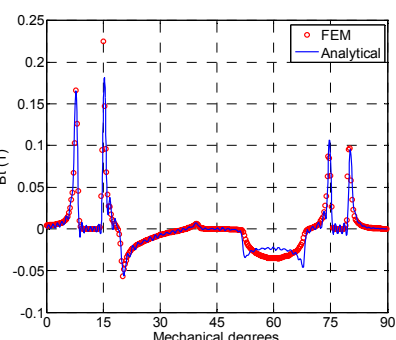

b)
Fig. 27. Radial (a) and tangential (b) flux density due to phase A, excitation current and permanent magnet in external rotor HE-FSM (Topology 1).

\section{E. Topology 2: External rotor 12/10 HE-FSM}

The same development as for internal rotor HE-FSM can be done for external rotor HE-FSM (Fig. 28) with introducing interfaces conditions and replacing outside region with the shaft region (19). Fig. 29 shows a comparison between analytical and FEM radial and tangential flux densities due to phase A current, permanent magnet and excitation current. The results are in very good agreement. However, it can be observed that high flux density levels up to $2 \mathrm{~T}$ are obtained. This indicates that the soft-magnetic material will be saturated and in general the flux density in the air gap will be lower. 


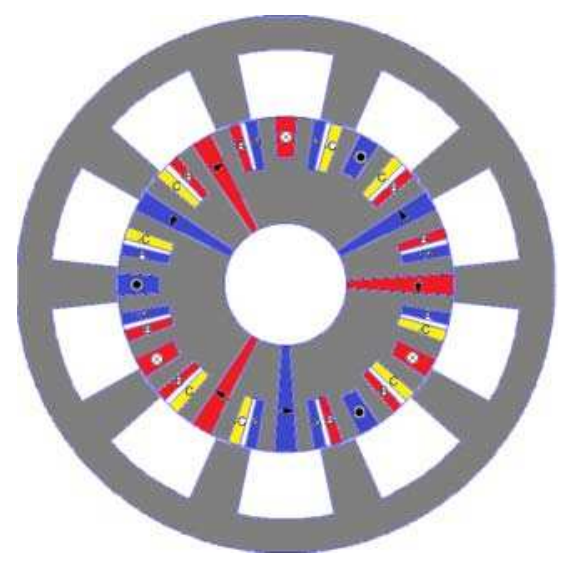

Fig. 28. Studied 12/10 external rotor HE-FSM (Topology 2).

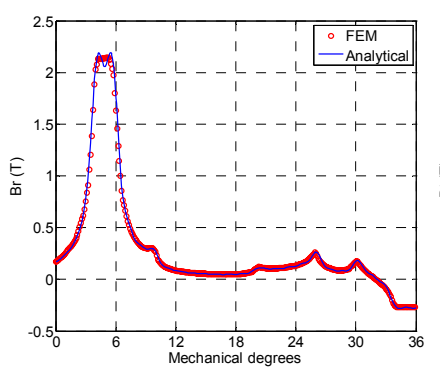

a)

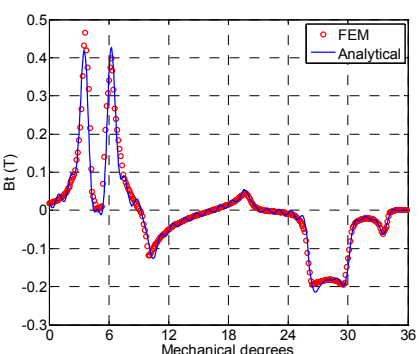

b)
Fig. 29. Radial (a) and tangential (b) flux density due to phase A, excitation current and permanent magnet in external rotor HE-FSM (Topology 2).

\section{F. Topology 1: 6/4 HE-FSM with Iron Flux Bridges}

The topology shown in Fig. 30 has 6 regions and 24 subdomains. The study is comparable with topology of Fig. 9 changing the general forms of vector potentials in excitation coil and permanent magnet as given by (4) and (11) and omitting interface condition between permanent magnet and excitation coil. Permanent magnet or excitation coil flux lines present a short circuit and no flux lines pass through the air gap. Analytical radial and tangential flux densities due to permanent magnet alone or excitation current alone are zero in the air gap. However, FEM give a small value of radial and tangential flux densities due to permanent magnet. Fig. 31 shows the radial and tangential flux densities due to armature current only where a very good agreement can be observed between analytical and FEM results. FEM prediction of magnetic field distribution due to armature reaction, excitation coil and permanent magnet gives a small difference with analytical results (Fig. 32). Analytical model which do not take into account the effect of modulating flux lines in the iron, gives zero magnetic field in the air gap when a short circuit exist.

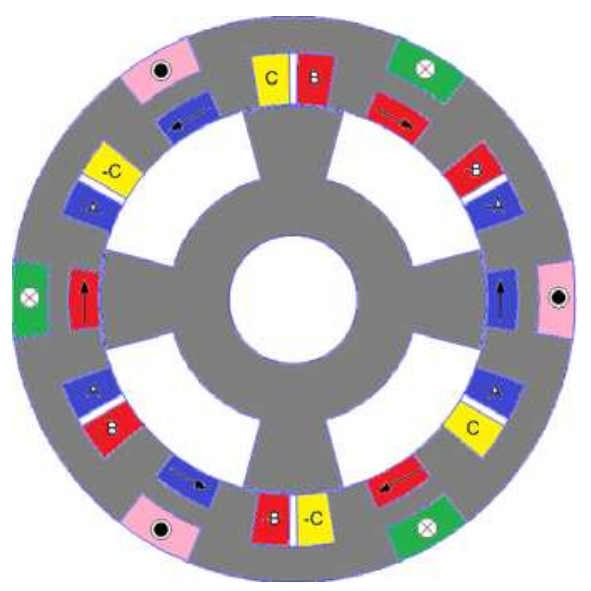

Fig. 30. Studied 6/4 internal rotor HE-FSM with iron flux bridges (Topology 1).

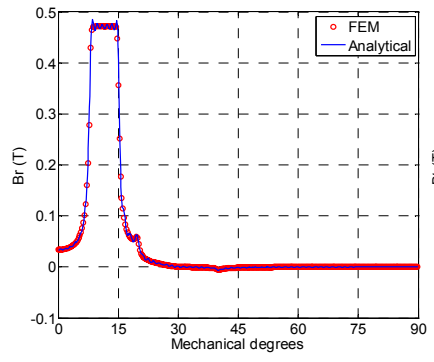

a)

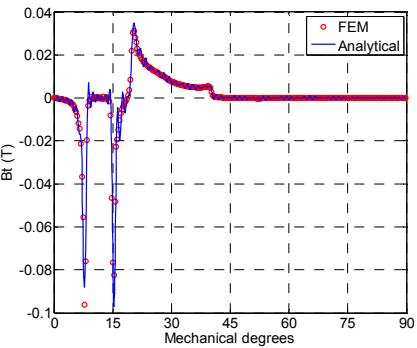

b)
Fig. 31. Radial (a) and tangential (b) flux density due to phase A current in internal rotor HE-FSM with iron flux bridges (Topology 1).

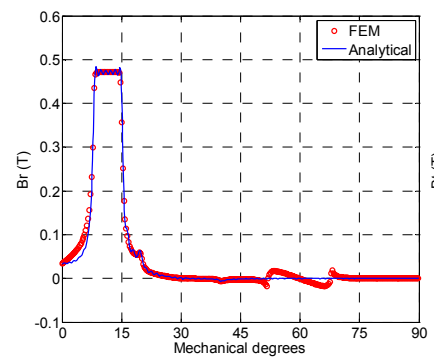

a)

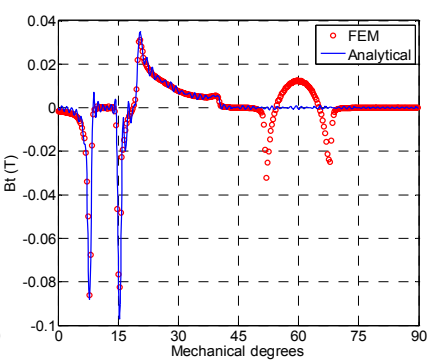

b)
Fig. 32. Radial (a) and tangential (b) flux density due to phase A, excitation current and permanent magnet in internal rotor HE-FSM with iron flux bridges (Topology 1).

The same development as above internal rotor HE-FSM is aplied for external rotor HE-FSM (Fig. 33) with replacing only the general form of outside machine subdomain with shaft region given by (19). Radial and tangential flux densities obtainend analytically and by FEM are in very good agreement when only phase A current exist (Fig. 34). 


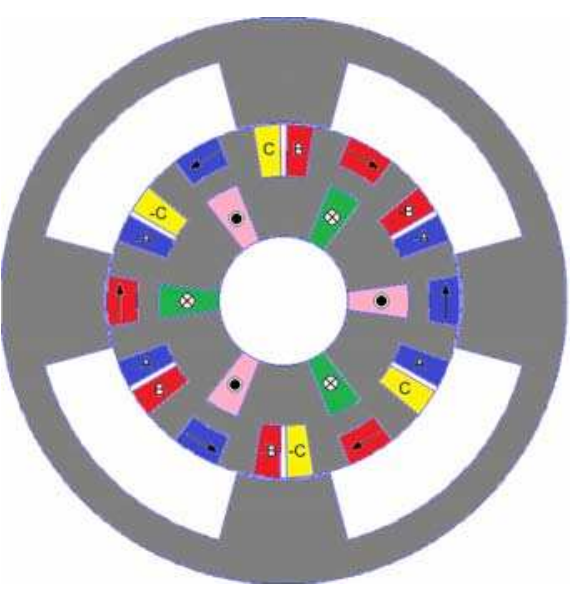

Fig. 33. Studied 6/4 external rotor HE-FSM with iron flux bridges (Topology 1).

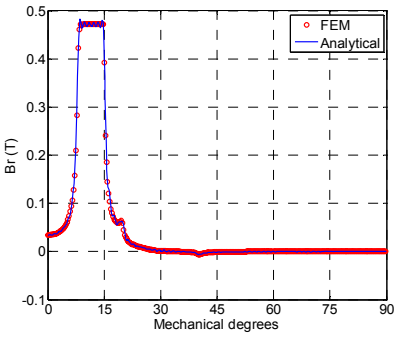

a)

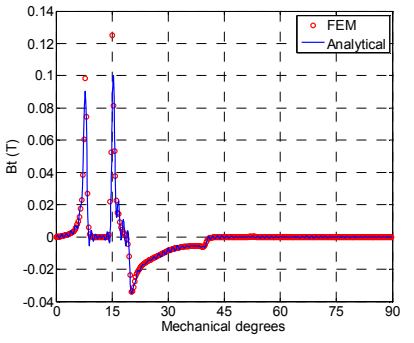

b)
Fig. 34. Radial (a) and tangential (b) flux density due to phase $\mathrm{A}$ in external rotor HE-FSM with iron flux bridges (Topology 1).

\section{G. Topology 2: 6/4 HE-FSM with Iron Flux Bridges}

This topology (Fig. 35) is studied extensivelly with FEM by [9]. It is interesting to predict magnetic field distribution analytically with dimensions and parameters variation. There are 23 subdomains. The general forms of vector potentials in each subdomain are given by equation (8) for double layer armature winding slots (6 subdomains), (8) for double layer excitation coil slots (6 subdomains), (10) for permanent magnet slots (6 subdomains), (16) for air gap (1 subdomain) and (13) for rotor slots (4 subdomains). Applying interfaces conditions at $R_{m}, R_{s}$ and $r_{3}$ permits to determine the vector potential in each subdomain. Flux lines due to permanent magnet only constitute a short circuit and analytical magnetic field in the air gap is then null. FEM permits to get in the air gap a small value of magnetic field when only permanent magnet is considered. Of course, analytical method can not take into account the effect of modulating flux by permanent magnet as FEM. When only phase A current and excitation current are considered, analytical and FEM results are in excellent agreement (Fig. 36).

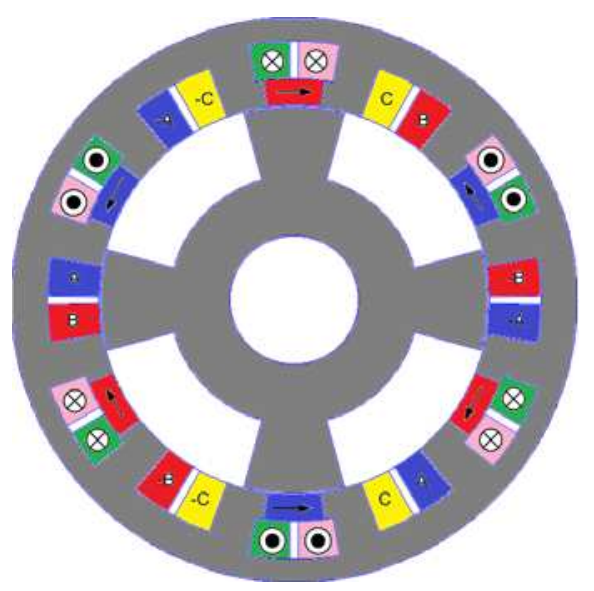

Fig. 35. Studied 6/4 internal rotor HE-FSM with iron flux bridges (Topology 2).

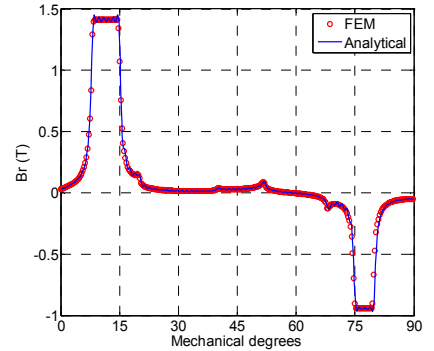

a)

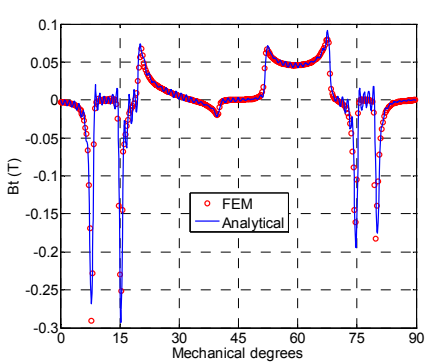

b)
Fig. 36. Radial (a) and tangential (b) flux density due to phase $\mathrm{A}$ and excitation current in internal rotor HE-FSM with iron flux bridges.

The same number of subdomains and general forms of vector potentials in each subdomain are used for external rotor HE-FSM (Fig. 37) study. Fig. 38, show radial and tangential flux densities due to phase A current and excitation current in the middle of air gap, where an excellent agreement is also observed.

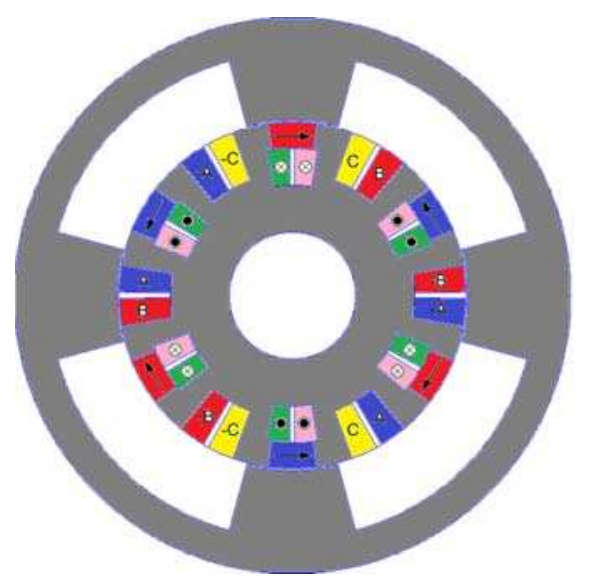

Fig. 37. Studied 6/4 external rotor HE-FSM. 


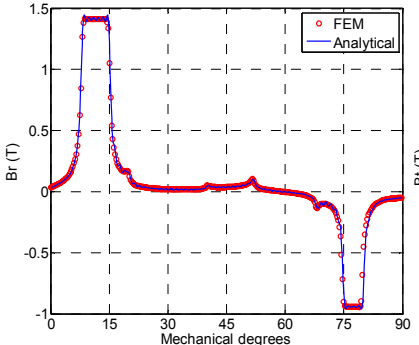

a)

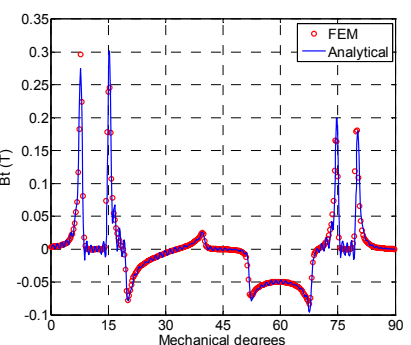

b)
Fig. 38. Radial (a) and tangential (b) flux density due to phase A and excitation current in external rotor HE-FSM with iron flux bridges.

\section{APPENDIX B}

The development of interfaces conditions in all studied FSM topologies uses this type of integration which can be found in [19] and are easy to calculate.

$$
\begin{aligned}
& \int_{g_{j}-\frac{a}{2}}^{g_{j}+\frac{a}{2}} \sin (n \theta) \cos \left(\frac{m \pi}{a}\left(\theta-g_{j}+\frac{a}{2}\right)\right) d \theta \quad(\mathrm{A}-1) \\
& \int_{g_{j}-\frac{a}{2}}^{g_{j}+\frac{a}{2}} \cos (n \theta) \cos \left(\frac{m \pi}{a}\left(\theta-g_{j}+\frac{a}{2}\right)\right) d \theta \\
& \int_{\beta_{k}+\frac{d}{2}}^{2} \cos \left(\frac{m \pi}{d}\left(\theta-\beta_{k}+\frac{d}{2}\right)\right) \cos \left(\frac{l \pi}{d}\left(\theta-\beta_{k}+\frac{d}{2}\right)\right) d \theta \text { (A-3) }
\end{aligned}
$$

\section{REFERENCES}

[1] M. Takeno, A. Chiba, N. Hoshi, S. Ogasawara, M. Takemoto and A. Rahman "Test Results and Torque Improvement of the 50-kW Switched Reluctance Motor Designed for Hybrid Electric Vehicles", IEEE Trans. Industry Applications., Vol. 48, No. 4, pp. 1327-1334, July/August 2012.

[2] M. Michon, S. Calverley and K. Atallah "Operating Strategies of Switched Reluctance Machines for Exhaust Gas Energy Recovery Systems", IEEE Trans. Industry Applications., Vol. PP, No. 99, pp. 1, 2012.

[3] A. Chiba and Y. Takano, M. Takeno, T. Imakawa, N. Hoshi, M. Takemoto and S. Ogasawara "Torque Density and Efficiency Improvements of a Switched Reluctance Motor Without Rare-Earth Material for Hybrid Vehicles", IEEE Trans. Industry Applications., Vol. 47, No. 3, pp. 1240-1246, May/June 2011.

[4] G. J. Li, X. Ojeda, S. Hlioui, E. Hoang, M. Gabsi and C. Balpe "Comparative Study of Switched Reluctance Motors Performances for Two Current Distributions and Excitation Modes", Industrial Electronics Annual Conference (IECON'09), pp. 4047-4052, 2009.

[5] W. Z. Fei, J. X. Shen and P. C. Luk "Design and analysis of a new outerrotor permanent-magnet flux-switching machine for electric vehicle propulsion", COMPEL: The international Journal for Computation and Mathematics in Electrical and Electronic Engineering, Vol. 30, No. 1, 2011, pp. 48-61.

[6] Y. Wang and Z. Deng "Hybrid Excitation Topologies and Control Strategies of Stator Permanent Magnet Machines for DC Power System", IEEE Trans. Industrial Electronics., Vol. 59, No. 12, pp. 46014616, 2012.
[7] Y. Wang, Z. Deng and X. Wang "A Parallel Hybrid Excitation FluxSwitching Generator DC Power System Based on Direct Torque Linear Control", IEEE Trans. Energy Conversion., Vol. 27, No. 2, pp. 308-317, June 2012.

[8] Y. Wang and Z. Deng "Comparison of Hybrid Excitation Topologies for Flux-Switching Machines", IEEE Trans. Magnetics., Vol. 48, No. 9, pp. 2518-2527, September 2012.

[9] E. Sulaiman, T. Kosaka and N. Matsui "High Power Density Design of 6-Slot--8-Pole Hybrid Excitation Flux Switching Machine for Hybrid Vehicled", IEEE Trans. Magnetics., Vol. 47, No. 10, pp. 4453-4456, October 2011.

[10] E. Ilhan, B. L. J. Gysen, J. J. H. Paulides and E. A. Lomonova "Analytical Hybrid Model for Flux Switching Permanent Magnet Machines", IEEE Trans. Magnetics., Vol. 46, No. 6, pp. 1762-1765, June 2010.

[11] W. Hua, G. Zhang, M. Cheng and J. Dong "Electromagnetic Performance Analysis of Hybrid-Excited Flux-Switching Machines by a Nonlinear Magnetic Network Model", IEEE Trans. Magnetics., Vol. 47, No. 10, pp. 3216-3219, October 2011.

[12] B. L. J. Gysen, E. Ilhan, K. J. Meessen, J. J. H. Paulides and E. A. Lomonova "Modeling of Flux Switching Permanent Magnet Machines With Fourier Analysis", IEEE Trans. Magnetics., Vol. 46, No. 6, pp. 1499-1502, June 2010.

[13] B. Gaussens, E. Hoang, O. de la Barriere, J. Saint-Michel and M. Gabsi "Analytical Approach for Air-gap Modeling of Field-Excited FluxSwitching machine: No-load Operation", IEEE Trans. Magnetics., Vol. 48, No. 9, pp. 2505-2517, 2012.

[14] B. Gaussens, E. Hoang, O. de la Barriere, J. Saint-Michel, P. Manfe, M. Lecrivain and M. Gabsi "Analytical Armature Reaction Field Prediction in Field-Excited Flux-Switching Machines using an Exact Relative Permeance Function”, IEEE Trans. Magnetics., Vol. PP, No. 99, pp. 1, 2012.

[15] L. J. Wu, Z. Q. Zhu, D. Staton, M. Popescu and D. Hawkins "An Improved Subdomain Model for Predicting Magnetic Field of SurfaceMounted Permanent Magnet Machines Accounting for Tooth-Tips", IEEE Trans. Magnetics., Vol. 47, No. 6, pp. 1693-1704, June 2011.

[16] L. J. Wu, Z. Q. Zhu, D. Staton, M. Popescu and D. Hawkins "Subdomain Model for Armature Reaction Field of Surface-Mounted Permanent Magnet Machines Accounting for Tooth-Tips”, IEEE Trans. Magnetics., Vol. 47, No. 4, pp. 812-822, April 2011.

[17] L. J. Wu, Z. Q. Zhu, D. Staton, M. Popescu and D. Hawkins "Analytical Prediction of Electromagnetic Performance of Surface-Mounted Permanent Magnet Machines Based on Subdomain Model Accounting for Tooth-Tips”, Electric Power Applications, IET, Vol. 5, No. 7, pp. 597-609, 2011

[18] L. Jian, K. T. Chau, Y. Gong, C. Yu and W. Li "Analytical Calculation of Magnetic Field in Surface-Inset Permanent Magnet Motors", IEEE Trans. Magnetics., Vol. 45, No. 10, pp. 4688-4691, October 2009.

[19] K. Boughrara, R. Ibtiouen and T. Lubin "Analytical Prediction of Magnetic Field in Parallel Double Excitation and Spoke-Type Permanent-Magnet Machines Accounting for Tooth-Tips and Shape of Polar Pieces", IEEE Trans. Magnetics., Vol. 48, No. 7, pp. 2121-2137, July 2012.

[20] B. L. J. Gysen, K. J. Meessen, J. J. H. Paulides and E. A. Lomonova "General Formulation of the Electromagnetic Field Distribution in Machines and Devices Using Fourier Analysis", IEEE Trans. Magnetics., Vol. 46, No. 1, pp. 39-51, January 2010.

[21] T. Lubin, S. Mezani and A. Rezzoug "Exact Analytical Method for Magnetic Field Computation in the Air Gap of Cylindrical Electrical Machines Considering Slotting Effects", IEEE Trans. Magnetics., Vol. 46, No. 4, pp. 1092-1099, April 2010.

[22] Z. Q. Zhu, L. J. Wu and Z. P. Xia "An Accurate Subdomain Model for Magnetic Field Computation in Slotted Surface-Mounted PermanentMagnet Machines", IEEE Trans. Magnetics., Vol. 46, No. 4, pp. 11001115, April 2010.

[23] T. Lubin, S. Mezani and A. Rezzoug "2-D Exact Analytical Model for Surface-Mounted Permanent-Magnet Motors With Semi-Closed Slots", IEEE Trans. Magnetics., Vol. 47, No. 2, pp. 479-492, February 2011.

[24] D. C. Meeker, Finite Element Method Magnetics. ver. 4.2 (1 Apr. 2009 Build) [Online]. Available: http://www.femm.info

[25] A. Bellara, Y. Amara, G. Barakat and B. Dakyo "Two-Dimensional Exact Analytical Solution of Armature Reaction Field in Slotted Surface Mounted PM Radial Flux Synchronous Machines", IEEE Trans. Magnetics., Vol. 45, No. 10, pp. 4534-4538, October 2009. 


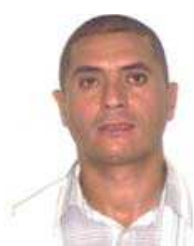

Kamel Boughrara was born in Algiers, Algeria, in 1969. He received the engineer diploma from Ecole Nationale Polytechnique, Algiers, Algeria, in 1994 and the magister degree from the University of Sciences and Technology Houari Boumediene in 1997, and the Doctorat d'Etat degree from Ecole Nationale Polytechnique, Algeria, in 2008. He is currently a Lecturer at the Université de Khemis Miliana, Algeria, at the Laboratoire de l'Energie et des systèmes intelligents (LESI). His interests include modeling and control of electrical machines and devices.

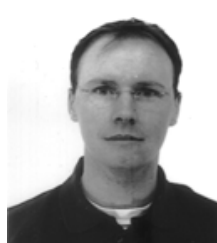

Thierry Lubin was born in Sedan, France, in 1970. He received the M.S. degree from the University of Paris 6 , France in 1994 and the Ph.D. degree from the University Henri Poincaré, Nancy, France, in 2003.

$\mathrm{He}$ is currently a lecturer of Electrical Engineering at the University of Nancy at the Groupe de Recherche en Electrotechnique et Electronique de Nancy. His interests include modeling and control of electrical machines and applied superconductivity in electrical devices.

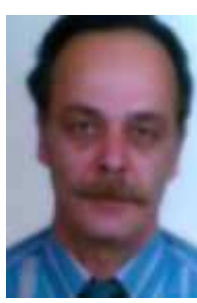

Rachid Ibtiouen received the Ph.D. degree in electrica engineering from Ecole Nationale Polytechnique (ENP) Algiers and from Institut National Polytechnique de Lorraine (INPL) France in 1993. From 1988 to 1993, he integrated the Groupe de Recherche en Electrotechnique et Electronique de Nancy (GREENancy). Between 1986 and 1999, he was Head of Electrical Engineering Department at ENP Algiers. From 2005 till 2008, he was Deputy Director in charge of Studies in ENP Algiers. Between 2009 and 2010, he was researcher and professor invited at UHP Nancy (France). From 1993 to 2011, he was an expert member of the committee on evaluation of the university projects of research (CNEPRU), with the ministry of the Algerian Higher education. He is currently Professor and Associated Director of Research with ENP Algiers. Since January 2005, he has been Director of the Research Laboratory of Electrical Engineering (LRE) in ENP. His fields of scientific interest include the modeling electric systems and drives, particularly electrical machines. 